\title{
A New Approach For Physically-Based Probabilistic Seismic Hazard Analysis For Portugal
}

Enrico Zacchei ( $\nabla$ enricozacchei@gmail.com )

Institute for Research and Technological Development in Construction

Reyolando Brasil

Universidade de Sao Paulo

\section{Research Article}

Keywords: PSHA, EGF, pb-PSHA, importance factors, attenuation equations, Portugal

Posted Date: June 17th, 2021

DOI: https://doi.org/10.21203/rs.3.rs-532918/v1

License: (9) This work is licensed under a Creative Commons Attribution 4.0 International License. Read Full License 
1 A New Approach for Physically-based Probabilistic Seismic Hazard Analysis for Portugal 2

3 Enrico Zacchei, $\mathrm{PhD}$, Researcher (a)

4 enricozacchei@gmail.com

5

6 Reyolando, M.L.R.F, Brasil, Full Professor (b, c)

$7 \quad$ reyolando.brasil@gmail.com

9 (a) Itecons - Institute for Research and Technological Development in Construction, Energy, 10 Environment and Sustainability, Rua Pedro Hispano s/n, 3030-289 Coimbra, Portugal

(b) Polytechnic School of São Paulo, University of São Paulo (USP), 380 Prof. Luciano

(c) Federal University of ABC (UFABC), Center for Engineering, Modeling and Applied Social

Abstract. Probabilistic seismic hazard analysis (PSHA) is nowadays the more complete analysis method to estimate the seismic input for structural analysis. However, it is strongly influenced by seismogenic parameters and attenuation equations. Here PSHA using empirical Green's functions (EGFs) with $2+2$ variables is carried out, which are correlated through the moment magnitude. This combination, already known as "physically-based PSHA (pbPSHA)", is an original approach that should be disseminated because it provides a good alternative in countries where the seismogenic zones and attenuation equations are not well known. The proposed model is based on linear faults, random, periodic, impulsive, linear source functions, and a punctual hypocentre. Differential equations are explained. Results are shown in terms of new seismic parameters, specific return periods and ground accelerations. The studied country is Portugal. It appears to the authors that no study has been published about pbPSHA for Portugal.

Keywords. PSHA; EGF; pb-PSHA; importance factors; attenuation equations; Portugal.

\section{Introduction}


The definition of seismic inputs has always been of interest to both geophysicists and engineers [79]. There are several procedures that provide seismic inputs for structures designing. These procedures can be deterministic, using elastic spectra from codes [7,8], synthetic spectra by attenuation equations [5,47], deterministic seismic hazard analysis [30,44], artificial accelerograms obtained from power spectrum density functions $[23,26]$, seismic coefficients by amplification of inertial forces [35], time-history analyses from database [19,21], spectrum compatible analyses by scaling factor [36,42,73].

The probabilistic procedures can be either the probabilistic seismic hazard analysis (PSHA) by Cornel model [2] or the physically-based PSHA (pb-PSHA) $[37,65]$, which is treated in this paper.

The pb-PSHA is mainly based on the PSHA, which is nowadays the more complete method to estimate the seismic input because it accounts for the seismotectonic and geological context and the probability of occurrence of earthquakes [30,38,39,40,41,43,45,73].

$\mathrm{Pb}-\mathrm{PSHA}$ follows the same procedures of standard PSHA with only one difference: attenuation equations are not used and are substituted by empirical Green's functions (EGFs) and computation of physically based seismograms and direct analysis accounting the hazard for structures [14].

EGFs allow to directly calculate the ground displacement at a site, defining wave path from the seismic source to the ground. However, it is not possible to know the characteristic of the soil $[22]$.

The studied area is Portugal where seismic activity is high. Since the 1755 Lisbon earthquake, several studies, including old ones $[56,57,58,59]$ up to the most recent $[60,61,62]$, have been developed. For Portugal, some papers have been published about PSHA $[5,6,63,64]$ but it appears to the authors that no study has been published about pb-PSHA.

The motivation of this study is the choice of a model and parameters to be correctly used.

"Random" uncertainties are related to the inherent randomness of the studied phenomena, whereas the "epistemic" uncertainties are related to the lack of knowledge of the models $[9,10]$. 
69

70

71

72

73

74

75

76

77

78

79

80

81

82

83

84

Random and epistemic uncertainties are studied in stochastic analyses, which are used to solve problems that cannot be deterministically solved because models are not completely known, or data are not available. However, when epistemic uncertainties are predominant with respect to random uncertainties, it is difficult to choose a unique model.

The specific motivations are summarized in the following three points.

1. Lack of a well-calibrated attenuation equation for Portugal. In this sense the use of EGFs to directly calculate the ground accelerations is advisable. In literature there are four attenuation laws for Portugal of which three are expressed in terms of seismic intensity due to the scarcity of instrumental data $[46,47,66]$ and one is expressed in terms of spectral accelerations [5] (see Table 1).

Table 1. Attenuation equations for Portugal.

\begin{tabular}{cc}
\hline Attenuation equation & Year \\
\hline $\mathrm{I}=0.98+0.85 \mathrm{M}-0.23 \mathrm{In}(\mathrm{R})-0.006 \mathrm{R}^{\mathrm{a}}$ & $1997[66]$ \\
$\mathrm{I}=6.8+1.13 \mathrm{M}-1.68 \mathrm{In}(\mathrm{R}+14)$ & $1999[46]$ \\
$\log _{10} \mathrm{PGA}=-0.74+0.55 \mathrm{M}-0.002 \log _{10} \mathrm{R}-0.61 \mathrm{R}+0.25$ & $2007[5]$ \\
$\mathrm{I}=-1.9438 \mathrm{In}(\mathrm{R})+4.1 \mathrm{M}-9.5763$ & $2014[47]$ \\
\hline
\end{tabular}

Note: $\mathrm{I}$ = Intensity. $\mathrm{M}=$ Considered magnitude. $\mathrm{R}=$ Considered distance. $\mathrm{PGA}=$ Peak ground acceleration.

${ }^{\text {a }}$ Values estimated for a specific zone: ZS5 for EC8 model (see Fig. 1).

These equations are very different from each other although they should be used for the same country. In this sense it is difficult to rely on these equations. In [48,49] other attenuation equations calibrated by using Portugal data are presented, however, these are not defined for this country.

2. There are four valid models for Portugal, what makes it difficult to choose the best. These models that characterize the seismogenic zones (ZS) are: Share, Ersta, EC8, Zesis [4,6,8] (see Fig. 1). In this sense, there are four models that provides different outputs, moreover, it has been noted in literature $[6,64,66,67]$ that for the same seismogenic zones of the same EC8 model, different values have been obtained. 


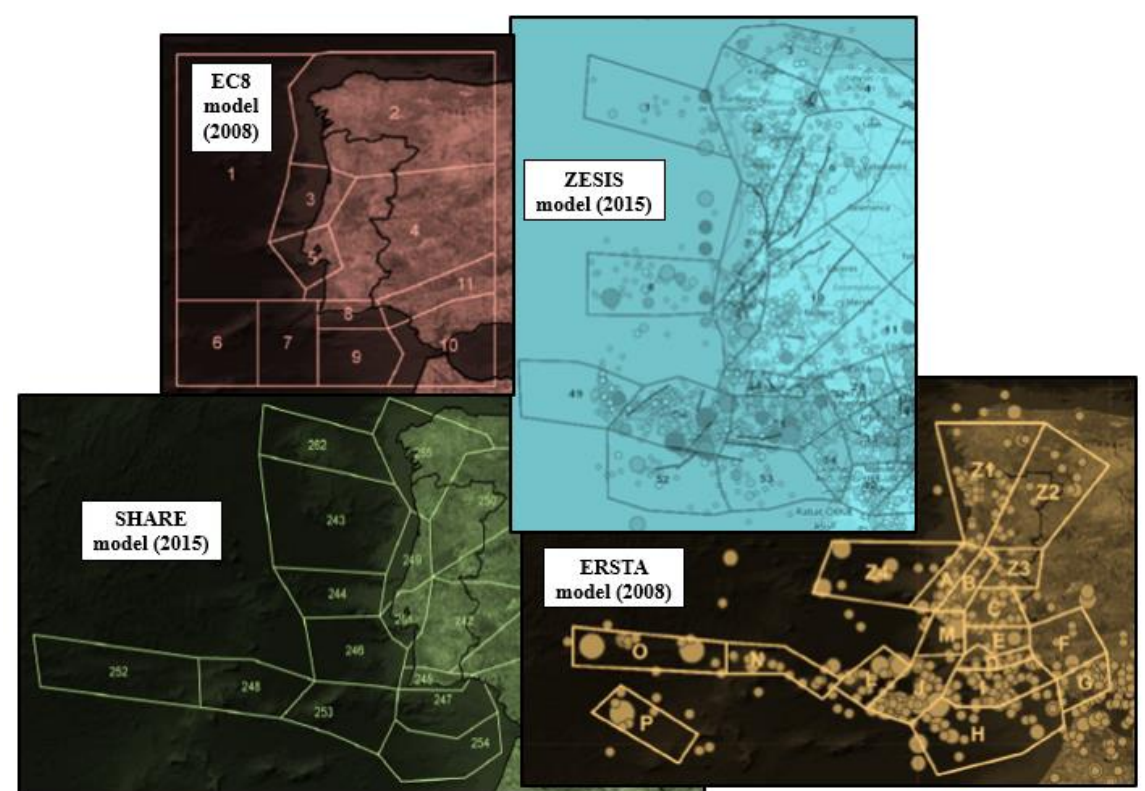

Figure 1. Seismogenic zones for Portugal: Share, Ersta, EC8, Zesis [4,6,8]

100

101 3. Inconsistency of the following relation: PGA $=\gamma_{I} \times P G A_{R}$, where $\gamma_{I}$ is the importance factor 102 and $\mathrm{PGA}_{\mathrm{R}}$ is the reference PGA [7,8,50]. This relation correlates an acceleration (PGA) with the type of construction (e.g. agricultural buildings, schools, power plants). Given that, as mentioned in $[50,76], \gamma_{I}$ is not related to the structure characteristics, this relation is inconsistent.

105 Thus, the logic to corelate the structure (object to be designed at surface) with a PGA (seismic 106 input in deep) should be exceeded because the two parameters are not corelated.

107 According to the authors, a more correct form to quantify the importance factor is treated in 108 literature where this factor is calibrated as a function of the vulnerability of the structures, 109 external loadings [75], evaluation of benefit/costs for the service-life [76], losses due to damage and failure of the structure [77].

\section{Materials}

\section{$113 \quad 2.1 \quad$ Materials for seismic hazard}

115 Four seismogenic zones have been selected, of which two are typically used only for Portugal, 116 as the Share and Ersta [6], one is based on Eurocode EC8 [6,8] and the other includes the Iberian 117 Peninsula Zesis [4].

119 From these seismogenic zones, data have been collected and used to calibrate new data 120 regarding 6 specific seismogenic zones. In particular, this analysis is based on the associated 
121 events that characterize the seismicity of each seismogenic zone for Zesis. The group of events

122 has been divided in sub-groups $\Delta \mathrm{M}_{\mathrm{w}}$, associated to a number of events with the same moment 123 magnitude $\mathrm{M}_{\mathrm{w}}$, completeness period, completeness interval, frequency of events of similar 124 intensity, mean annual rate of exceedance $\lambda_{c}$, return period $1 / \lambda_{c}$, and $\log _{10} \lambda_{c}$.

125

126 The events provided by Zesis have already been processed for homogenization, declustering 127 and completeness [3,30]. Therefore, these operations have not been repeated. Thus, all events 128 have been taken as they are with the registered $\mathrm{M}_{\mathrm{w}}$ and, for the completeness period, the oldest year has been considered.

130

$131 \lambda_{c}$ of events with magnitude $\mathrm{M}_{\mathrm{w}}$ is correlated by the following Gutenberg-Richter (G\&R) law 132 [1]:

$134 \log _{10} \lambda_{\mathrm{c}}=\mathrm{a}+\mathrm{bM}_{\mathrm{w}}$

135

136

where the b-value describes the ratio between the number of small and large events, whereas the a-value measures the level of seismicity.

Table 2 shows the selected ZSs regarding continental Portugal and the equivalence between

140 them in terms of nomenclatures.

142 Table 2. Equivalences between the seismogenic zones (ZSs).

\begin{tabular}{cccc}
\hline ZS for Share [6] & ZS for Zesis [4] & ZS for Ersta [6] & ZS for EC8 [6] \\
\hline 242 (Évora) $^{\text {a }}$ & 10 & C, E and Z3 & 4 \\
245 (Algarve) & 13 & D & 8 \\
249 (Coimbra) & 7 & A and B & 3 \\
250 (Villa Real) & 6 & Z2 and B & 2 and 4 \\
251 (Lisbon) & 9 & B & 5 \\
255 (Braga) & 2 & Z1 & 2 \\
\hline
\end{tabular}

${ }^{a}$ In bracket is indicated a place of reference (city or region).

146 Table 3 lists the parameters collected from literature and obtained in this analysis. b-value 147 ranges from 0.64 to 1.06 (underlined value). b-value is considered as the universality value, i.e. considering the reference value $\mathrm{b}=1.0$, when $\mathrm{b}<1.0$ the area is more dominated by large but 
149 infrequent events and the small earthquakes have a lower frequency compared to the strong 150 earthquakes.

152 Table 3. Comparison of the models (b-value).

\begin{tabular}{ccccccc}
\hline $\begin{array}{c}\text { ZS } \\
(\text { Zesis) }\end{array}$ & $\begin{array}{c}\text { b-value } \\
\text { (Share) [6] }\end{array}$ & $\begin{array}{c}\text { b-value } \\
\text { (Zesis) [4] }\end{array}$ & $\begin{array}{c}\text { b-value } \\
\text { (Ersta) [6] }\end{array}$ & $\begin{array}{c}\text { b-value } \\
(\text { EC8) [6] }\end{array}$ & $\begin{array}{c}\text { b-value } \\
\text { (mean) }^{\mathbf{a}}\end{array}$ & $\begin{array}{c}\text { b-value } \\
\text { (this analysis) }\end{array}$ \\
\hline 10 & 1.00 & 1.00 & 0.99 & $0.82(0.84)$ & 0.953 & 0.97 \\
13 & 1.00 & $\underline{1.06}$ & 0.75 & $0.77(\underline{0.64)}$ & 0.895 & 0.83 \\
7 & 1.00 & 1.06 & 0.88 & $0.86(0.89)$ & 0.949 & 1.04 \\
6 & 1.00 & 0.98 & 0.94 & $0.82(0.84)$ & 0.934 & 0.83 \\
9 & 0.90 & 0.87 & 0.79 & $0.71(0.95)$ & 0.818 & 0.72 \\
2 & 1.00 & 1.04 & 0.98 & $0.66(0.84)$ & 0.920 & 0.88 \\
\hline
\end{tabular}

153

154

155

156

157

158

159

160

161

162

163

164

165

166

167

168

169

170

171

172

173

174

175

a The mean value refers to the values of Share, Zesis, Ersta, EC8 (except values in bracket).

${ }^{\mathrm{b}}$ In bracket there are the values estimated for the same seismogenic zones and model by other authors [64,66,67].

It is possible to see that, in Table 3, by the EC8 model, two different values for each ZS have been estimated $[6,64,66,67]$. This clearly confirms the difficulty in estimating a unique value, although the model and the area are the same (the total mean difference is about $7 \%$ ).

A difference between a mean of b-values calculated by Share, Zesis, Ersta, EC 8 models and the b-values calculated in this analysis is 0.033 (3.75\% error). This indicates a good calibration.

Figure 2 shows the G\&R trend by Eq. (1) for each ZS for Zesis. The solid line is the R\&G trend with $\mathrm{b}=1.0$ [20]. Each point represents the pre-defined sub-groups $\Delta \mathrm{M}_{\mathrm{w}}$. 


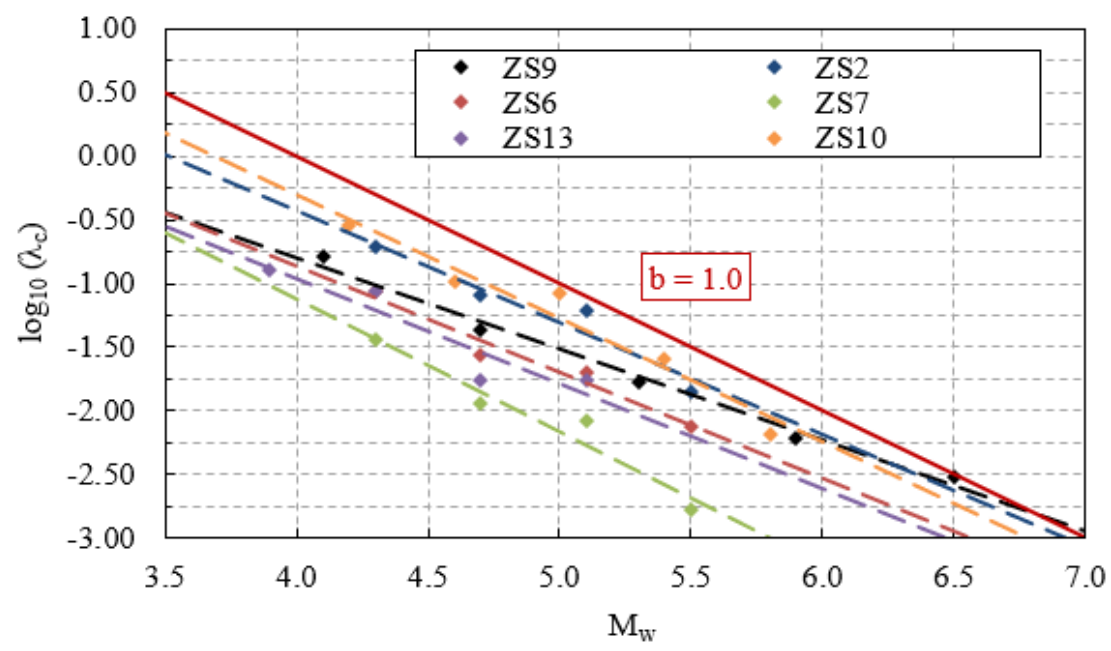

177 Figure 2. G\&R of this analysis for each ZS for Zesis.

178

179 Table 4 shows a-values for all models. The range of a-value is $2.27-3.60$ (underlined value).

180 In fact, a-values are generally of the order of 3.0 [8]. A good calibration for a-values is more

181 complicated because a small variation of $b$-values provides a large variation of a-values at $\mathrm{M}_{\mathrm{w}}$

$182=0$. Here the difference is 0.252 (9.09\% error).

183

184 Table 4. Comparison of the models (a-value).

\begin{tabular}{|c|c|c|c|c|c|c|}
\hline $\begin{array}{c}\text { ZS } \\
(\text { Zesis })\end{array}$ & $\begin{array}{c}\text { a-value } \\
\text { (Share) [6] }\end{array}$ & $\begin{array}{c}\text { a-value } \\
\text { (Ersta) [6] }\end{array}$ & $\begin{array}{c}\text { a-value } \\
\text { (EC8) [6] }\end{array}$ & $\begin{array}{l}\text { a-value } \\
\text { (mean) }^{a}\end{array}$ & $\begin{array}{l}\text { a-value } \\
\text { (Zesis) b }\end{array}$ & $\begin{array}{c}\text { a-value } \\
\text { (this analysis) }\end{array}$ \\
\hline 10 & 3.32 & 2.97 & 2.94 & 3.078 & 3.51 & 3.58 \\
\hline 13 & 3.00 & $\underline{2.27}$ & 2.56 & 2.610 & 3.41 & 2.35 \\
\hline 7 & 3.10 & 3.22 & 2.64 & 2.987 & 3.13 & 3.05 \\
\hline 6 & $\underline{3.60}$ & 3.45 & 2.94 & 3.328 & 3.31 & 2.48 \\
\hline 9 & 3.40 & 3.03 & 2.41 & 2.947 & 2.90 & 2.06 \\
\hline 2 & 3.30 & 3.56 & 2.64 & 3.167 & 3.80 & 3.09 \\
\hline
\end{tabular}

185

${ }^{\mathrm{a}}$ The mean value refers to the values of Share, Ersta, EC8.

186

${ }^{\mathrm{b}}$ Estimated value from b-value.

189 Table 5 shows $\lambda_{\mathrm{c}}$-values only for models with available data. This parameter, whose range is $1900.04-0.32$ (underlined value), is strongly influenced by the number of events to be considered 191 with the same $\mathrm{M}_{\mathrm{w}}$. Here a poor calibration is obtained, with a difference of 0.07 (47\% error).

192 However, to quantify the error only data from Zesis were available. 
194 Table 5. Comparison of the models ( $\lambda_{\mathrm{c}}$-value).

\begin{tabular}{ccc}
\hline $\begin{array}{c}\text { ZS } \\
(\text { Zesis })\end{array}$ & $\begin{array}{c}\boldsymbol{\lambda}_{\mathbf{c}} \\
(\text { Zesis })[4]\end{array}$ & $\begin{array}{c}\boldsymbol{\lambda}_{\mathbf{c}} \\
\text { (this analysis) }\end{array}$ \\
\hline 10 & 0.28 & 0.28 \\
13 & 0.13 & 0.13 \\
7 & 0.16 & $\underline{0.04}$ \\
6 & 0.19 & 0.09 \\
9 & 0.24 & 0.16 \\
2 & $\underline{0.32}$ & 0.19 \\
\hline
\end{tabular}

195

\subsection{Materials for Green's function}

197

198 Two main input parameters are necessary to develop the EGF: the fault and the seismic source.

199 In the ZSs, the fault is characterized by a dominant tectonic, stress regime and main focal 200 mechanism. The distance from the epicentre and edge of the fault rupture area is $\Delta<30 \mathrm{~km}$.

201 The source provides a list of events with a specific location, seismic moment $\mathbf{M}_{0}, \mathrm{M}_{\mathrm{w}}$ and other 202 parameters listed in Table 6.

203

204

205

206

207

208

209

210

211

212

213

214

215

216

217

218

219

220 
222 Table 6. Used seismic events retrieved from database $[19,21]$.

\begin{tabular}{|c|c|c|c|c|}
\hline \multirow{2}{*}{$\begin{array}{l}\text { Datum } \\
\text { Region: }\end{array}$} & \multicolumn{4}{|c|}{ Event } \\
\hline & Évora & Leiria & Lisbon & Lisbon \\
\hline Date, time: & $15 / 01 / 2018,11: 51$ & 30/04/1999, 9:00 & $17 / 08 / 2017,6: 44$ & $16 / 10 / 2000,3: 22$ \\
\hline Latitude, longitude: & $38.79,-7.93$ & $39.82,-8.96$ & $39.11,-8.92$ & $38.70,-9.15$ \\
\hline ZS for Zesis [4]: & 10 & 7 & 9 & 9 \\
\hline Depth, $\Delta(\mathrm{km}):$ & 11.0 & 22.9 & 12.0 & 20.3 \\
\hline $\mathrm{M}_{\mathrm{w}}:$ & $5.4^{*}$ & $4.7 *$ & $5.0^{*}$ & $4.0^{*}$ \\
\hline $\mathrm{M}_{0}(\mathrm{~N} \times \mathrm{m}):$ & $1.49 \times 10^{24 *}$ & $1.39 \times 10^{23 *}$ & $3.85 \times 10^{23 *}$ & $1.30 \times 10^{22 *}$ \\
\hline Style of faulting: & N/A & N/A & N/A & N/A \\
\hline PGA $\left(\mathrm{cm} / \mathrm{s}^{2}\right):$ & 1.24 & 28.75 & 0.152 & 5.70 \\
\hline PGV $(\mathrm{cm} / \mathrm{s})$ : & 0.09 & 2.11 & 0.01 & 0.33 \\
\hline PGD (cm): & 0.01 & 0.14 & 0.0 & 0.02 \\
\hline PSA $_{\max }$ : & 6.79 & 110.17 & 0.639 & 16.37 \\
\hline$f_{\text {,max }}(\mathrm{Hz})$ : & 1.691 & 1.27 & 1.721 & 2.216 \\
\hline$f_{\text {,min }}(H z):$ & 0.003 & 0.012 & 0.03 & 0.06 \\
\hline $\mathrm{T}_{\mathrm{s}}(\mathrm{s}):$ & 27.24 & 13.66 & 46.04 & 16.61 \\
\hline
\end{tabular}

223 Note: *Estimated value. N/A = Not available. PGA = Peak ground acceleration. PGV = Peak

224 ground velocity. $\mathrm{PGD}=$ Peak ground displacement. PSA $_{\max }=$ Maximum pseudo-spectral 225 acceleration. $\mathrm{f}=$ Frequency of the Fourier amplitudes. $\mathrm{T}_{\mathrm{s}}=$ Significant duration $(5-95 \%$ Arias 226 intensity [78]).

229 For some events, database [21] provides a local magnitude $\mathrm{M}_{\mathrm{L}}$ instead of $\mathrm{M}_{\mathrm{w}}$, which is mostly 230 used for this type of analysis. From the literature [31,32], it is known that a unique global 231 relation between $\mathrm{M}_{\mathrm{L}}-\mathrm{M}_{\mathrm{w}}$ does not exist. However, a more recent relation has been calibrated 232 [68], in which a discrepancy of $\sim 0.49$ has been noted. $M_{0}$ has been calculated in accordance to 233 the literature [33].

235 The style of faulting is not available (N/A) by database. However, the reference stress regime 236 can be taken from the respective ZSs where the event happened.

238 Figure 3 shows accelerograms in time $\ddot{u}(t)$, the Fourier amplitude as function of the frequency, $239 \mathrm{f}$, and the PSAs in function of structural periods, T. Four earthquakes have been processed by 240 software [24] and plotted for $\mathrm{T}_{\mathrm{s}}$ of the 5-95\% Arias intensity [78]. Although they are quite 
241 "clean" recordings, the linear baseline correction and filtering with butterworth type filter and 242 bandpass configuration $(0.50-25.0 \mathrm{~Hz})$ have been applied.

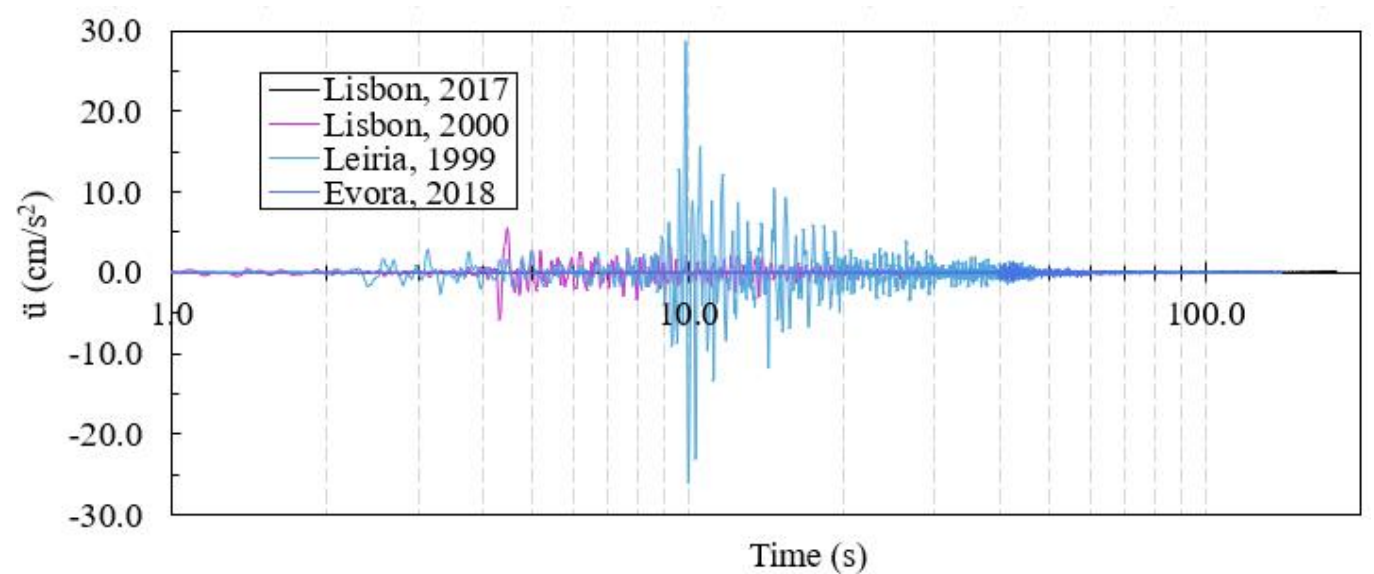

(a)

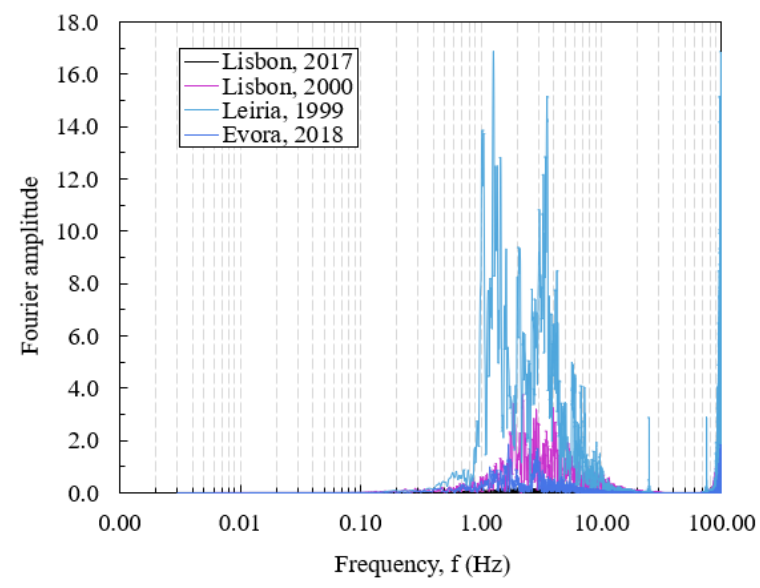

(b)

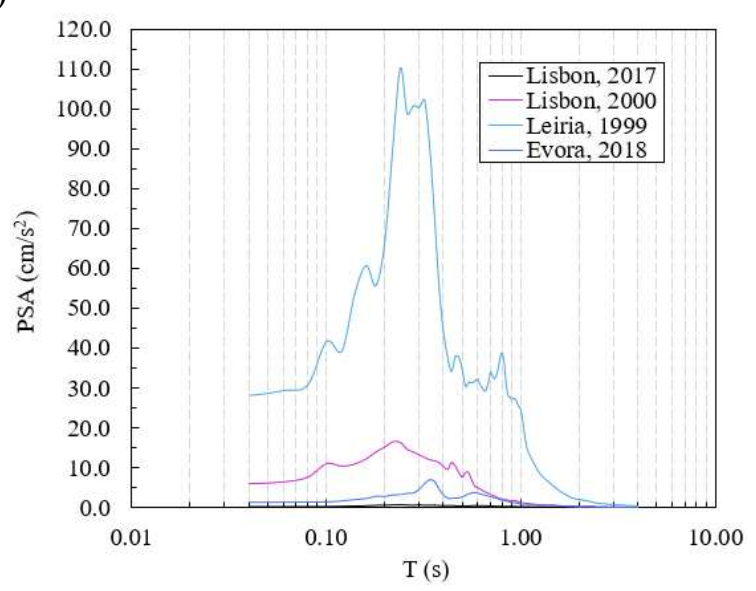

(c)

244 Figure 3. Accelerograms $\ddot{u}(\mathrm{t})$ in the time $\mathrm{t}(\mathrm{a})$; Fourier amplitude vs. $\mathrm{f}(\mathrm{b})$; PSA vs. structural 245 period $\mathrm{T}(\mathrm{c})$ for four selected earthquakes.

Fig. 4 shows the location of the epicentre (star) and the station (triangle) where the PGA has been registered of the four earthquakes. It is possible to see that the distances are so great as to pass from a ZS to other ZS. The distances are, from left to right in Fig. 4, $14.2 \mathrm{~km}, 181.6 \mathrm{~km}$, $185.5 \mathrm{~km}, 80.8 \mathrm{~km}$. 

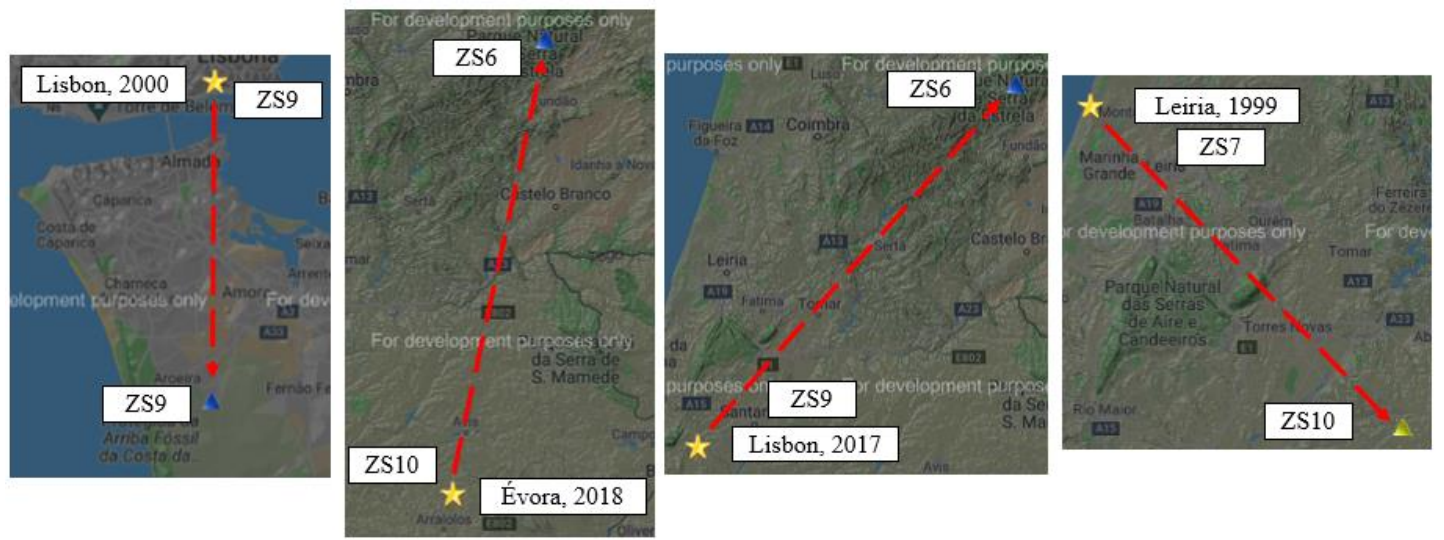

Figure 4. Location of the epicentre (star) and station (triangle) for the four earthquakes.

260 Other events have been selected in order to understand, in a qualitative way, seismic registration

261 in Portugal. From these events the relations in Table 6 between $M_{w} / M_{0}, M_{L} / M_{w}$ have been 262 calibrated. These events, that happened in Azores islands (outside of the considered 263 seismogenic zones) at $10.0 \mathrm{~km}$ depth, are:

1. 01/08/2000, 4:35 date; $38.79,-29.0$ latitude, longitude; $5.1 \mathrm{M}_{\mathrm{w}} ; \mathrm{M}_{0}=5.10 \times 10^{23} \mathrm{~N} \times \mathrm{m}$; 266 strike-slip style of faulting.

267 2. 09/07/1998, 5:19 date; 38.65, -28.62 latitude, longitude; $6.2 \mathrm{M}_{\mathrm{w}} ; \mathrm{M}_{0}=1.60 \times 10^{21} \mathrm{~N} \times \mathrm{m}$; 268 strike-slip style of faulting.

269 3. 27/06/1997, 4:39 date; 38.33, -26.68 latitude, longitude; $5.9 \mathrm{M}_{\mathrm{w}} ; \mathrm{M}_{0}=6.8 \times 10^{24} \mathrm{~N} \times \mathrm{m}$; 270 normal style of faulting.

271 4. 01/01/1980, 16:42 date; 38.81, -27.78 latitude, longitude; $6.9 \mathrm{M}_{\mathrm{w}} ; \mathrm{M}_{0}=2.82 \times 10^{26} \mathrm{~N} \times \mathrm{m}$; 272 strike-slip style of faulting.

\section{Methodologies}

275

276 The general methodology is divided in two processes, i.e. PSHA + EGF, which are correlated 277 to each other by $\mathrm{M}_{\mathrm{w}}$, that provide pb-PSHA (see Fig. 5). By this methodology the first and 278 second problem described in the introduction could be overcome. 


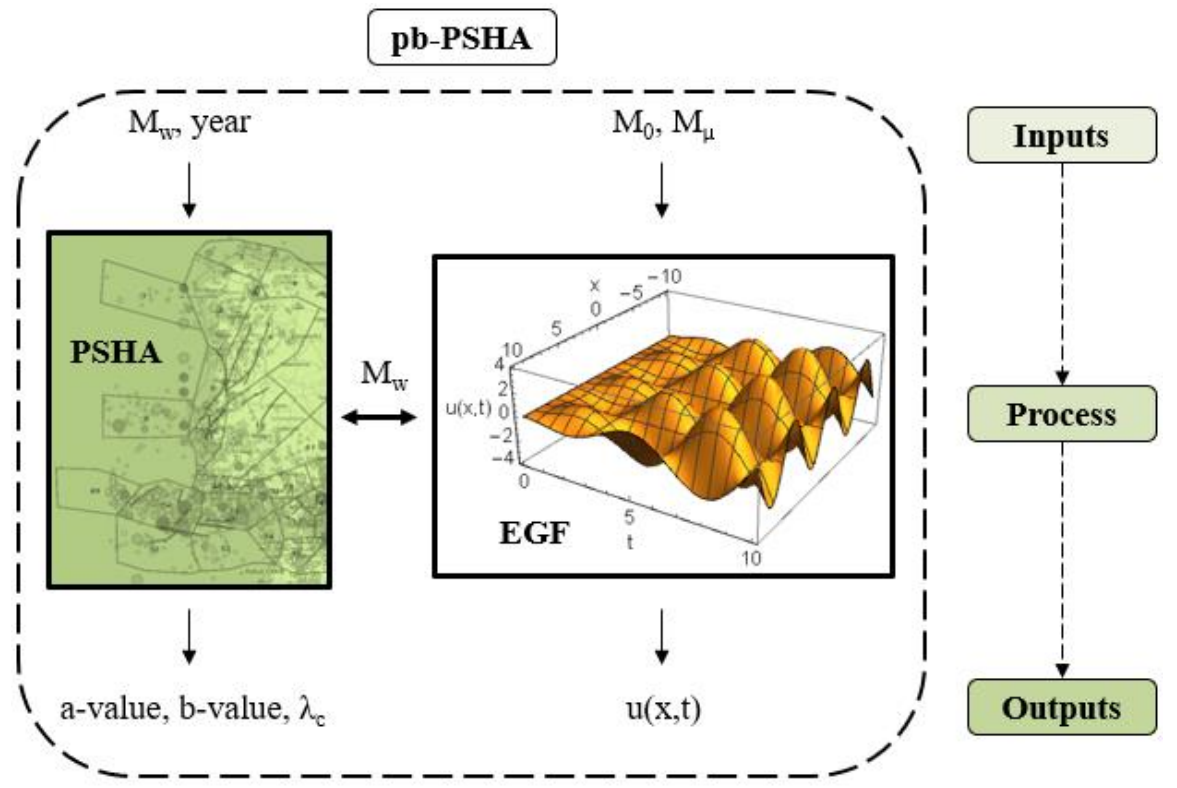

Figure 5. General methodology for PSHA + EGF $\equiv$ pb-PSHA.

The general methodology, in Fig. 5, illustrates the main inputs of both models, that inserted in the corresponding process, provides the outputs. Both models are correlate to $\mathrm{M}_{\mathrm{w}}$, which is treated as a probabilistic parameter in PSHA and as a physical parameter in EGF.

For the PSHA the input data are $\mathrm{M}_{\mathrm{w}}$ and year, whereas the output data are a-value, b-value, $\lambda_{\mathrm{c}}$. data are $\mathrm{M}_{0}$ and $\mathrm{M}_{\mu}$ (latter explained), whereas the output data are the ground motions $u(x, t)$.

Fig. 6 shows the interdependencies of all parameters involved in both methods. The parameters in green indicate that can be calculated in direct way, in yellow in indirect way and in red are not calculated. These parameters are treated in literature $[51,54,74]$. 


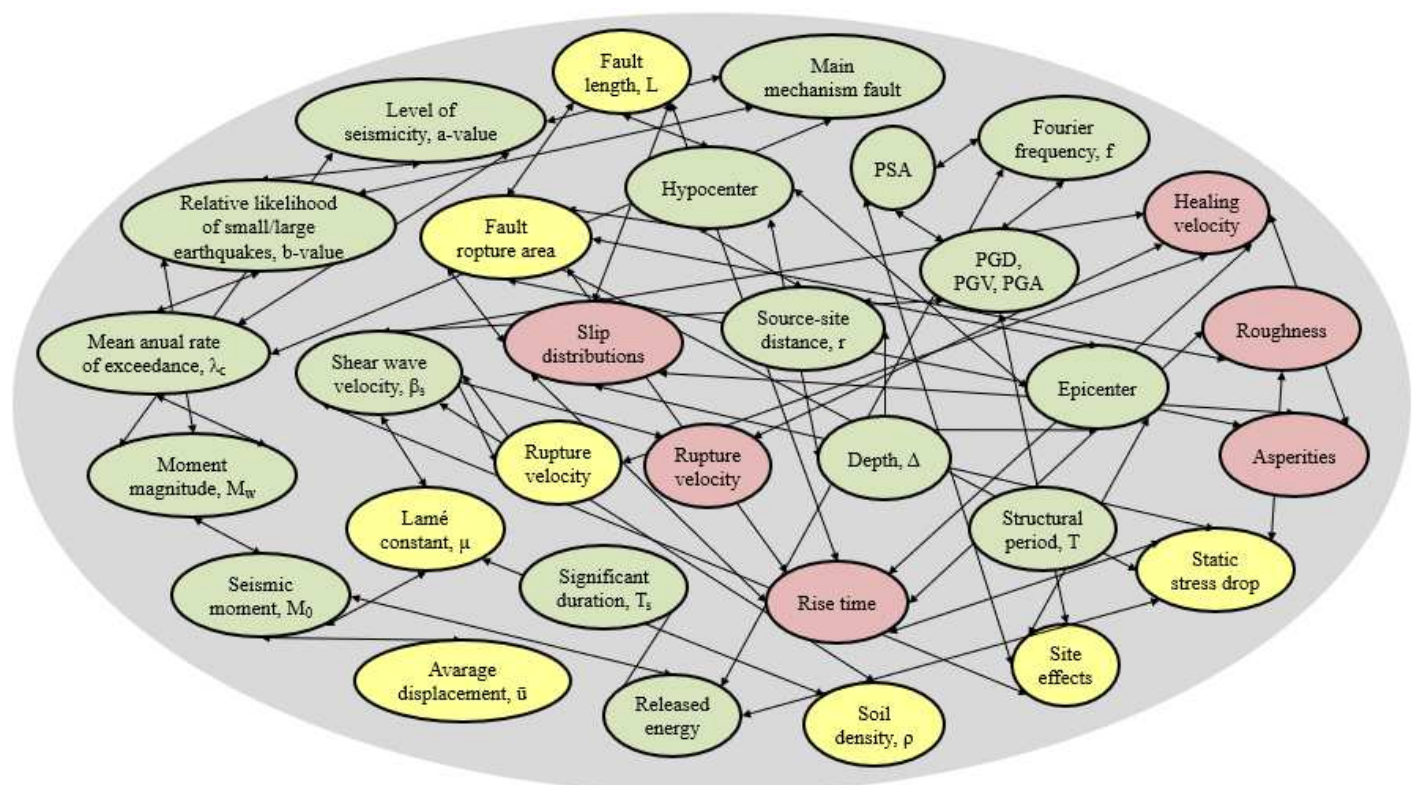

304 Figure 6. Interdependencies of parameters directly calculated (in green), indirectly calculated 305 (in yellow), no calculated (in red).

\subsection{Seismic hazard}

The PSHA is based on the Cornell method [2] and the Poisson distribution [34]. A truncated exponential probability density function (PDF) at the minimum, $\mathbf{M}_{\mathrm{w}, \min }$, and maximum magnitude moment $\mathrm{M}_{\mathrm{w}, \max }$, is used. The probability of exceedance $\mathrm{P}_{\mathrm{e}}$ of several magnitudes, $\mu_{\mathrm{w}, \mathrm{i}}$, associated to a specific seismogenic zone and correlated to a PDF for source-side distance $r$ in a range $r_{\min } \leq r \leq r_{\max }, f_{R}(r)$, is described by $[3,73]$ :

$\mathrm{P}_{\mathrm{e}}\left[\mathrm{M}_{\mathrm{w}}>\mu_{\mathrm{w}, \mathrm{i}}\right]=\int_{r_{\text {min }}}^{r_{\max }} \mathrm{P}_{\mathrm{e}}\left[\mathrm{M}_{\mathrm{w}}>\mu_{\mathrm{w}, \mathrm{i}}\right] f_{R}(r) d r=$

$\int_{r_{\min }}^{r_{\max }}\left(\frac{\mathrm{e}^{-\left(\beta\left(\mu_{\mathrm{w}, \mathrm{i}}-\mathrm{M}_{\mathrm{w}, \min }\right)\right.}-\mathrm{e}^{-\left(\beta\left(\mathrm{M}_{\mathrm{w}, \max }-\mathrm{M}_{\mathrm{w}, \min }\right)\right.}}{1-\mathrm{e}^{-\beta\left(\mathrm{M}_{\mathrm{w}, \max }-\mathrm{M}_{\mathrm{w}, \min }\right)}}\right) \frac{r}{L \sqrt{r^{2}-\Delta^{2}}} d r \approx$

$\frac{\mathrm{e}^{-\left(\beta\left(\mu_{\mathrm{w}, \mathrm{i}}-\mathrm{M}_{\mathrm{w}, \min }\right)\right.}-\mathrm{e}^{-\left(\beta\left(\mathrm{M}_{\mathrm{w}, \max }-\mathrm{M}_{\mathrm{w}, \min }\right)\right.}}{1-\mathrm{e}^{-\beta\left(\mathrm{M}_{\mathrm{w}, \max }-\mathrm{M}_{\mathrm{w}, \min }\right)}}$

where $\mathrm{L}$ is the fault length, $\Delta$ is the vertical projection of the fault at ground surface, $\beta=b$ $\log _{\mathrm{e}} 10$. PDF of $\mathrm{f}_{\mathrm{R}}(\mathrm{r})$ is expressed by an equation that models a shallow fault as a linear source.

The probability of not-exceedance $\mathrm{P}_{\mathrm{ne}}$ and the return period $\mathrm{T}_{\mu \mathrm{w}, \mathrm{i}}$ are defined, respectively, as: 


\subsection{Empirical Green functions}

\subsubsection{Basic hypotheses of the model}

The use of EGFs is based on the literature [17,28,52] where EGF only represents the medium, through the effects of propagation. EGF is a vector record that includes the seismic source. For the definition of seismic source, events small enough are used that the frequency of interest is below the source corner frequency, so that the source of the EGF is a step function, which it is removed by deconvolution. Therefore, EGF is convolved with the source function. If it is not possible to find events small enough, it is deconvolved out a Brune source [37], which work for small magnitude $(<4.0)$, to obtain the propagation of EGF.

In this study, the approach is similar but somewhat different. Here, the EGF is a vector that accounts for the contribution of wave equations, whereas the source function is defined by another function that is convoluted with the EGF. In this way, EGF is inserted directly into the elasto-dynamic equation, as detailed in the following section. Often, the source is at a point in space or time, so that the seismic source contains delta functions and is easily integrated. A feature of this formulation is that the principle of reciprocity, which says that the source and the receiver can be interchanged, emerges directly [28].

\subsubsection{Theory}

The general analysis of displacements discontinuities across an internal surface $\Omega$ is treated in this section. Here, the discussed aspect is to pass from a surface $\Omega$ to a line x' (see Annex).

EGFs for a time-dependent $\mathrm{t}$ differential operator $\mathcal{L}(\mathrm{u}(\mathrm{x}, \mathrm{t}))$ over the region $\Omega$ is defined to be a solution $\mathrm{g}\left(\mathrm{x}^{\prime}, \mathrm{t}^{\prime} ; \mathrm{x}, \mathrm{t}\right)$ of $\mathcal{L}\left(\mathrm{g}\left(\mathrm{x}^{\prime}, \mathrm{t}^{\prime} ; \mathrm{x}, \mathrm{t}\right)\right)=\delta\left(\mathrm{x}-\mathrm{x}^{\prime}\right) \delta\left(\mathrm{t}-\mathrm{t}^{\prime}\right)$, by the Dirac delta function $\delta$ [17], that satisfies the given homogeneous boundary conditions $\mathcal{B}(\mathrm{u}(\mathrm{x}, \mathrm{t}))[17,18,25]$. A particular solution of $\mathcal{L}(\mathrm{u}(\mathrm{x}, \mathrm{t}))=\mathrm{f}(\mathrm{x}, \mathrm{t})$ with homogeneous boundary $\mathcal{B}(\mathrm{u}(\mathrm{x}, \mathrm{t}))$ in a general medium can be obtained by performing a convolution integral: 
$\int_{0}^{\infty} d t^{\prime} \int_{x^{\prime} \in \Omega} f\left(x^{\prime}, t^{\prime}\right) g\left(x^{\prime}, t^{\prime} ; x, t\right) d x^{\prime}$

360 The elastic-dynamic equation of an earthquake and its ground motions is here represented. The ground displacement, $\mathrm{u}(\mathrm{x}, \mathrm{t})$, in the direction $\hat{x}_{n}$, at location $\mathrm{x}$ and time $\mathrm{t}>0$ is [11]:

where $\mathrm{f}\left(\mathrm{x}^{\prime}, \mathrm{t}^{\prime}\right)$ is a seismic source function in the $\hat{x}_{q}$ direction, at location $\mathrm{x}^{\prime}$ (三 L in Eq. (2)) and time t', and $\mathrm{g}\left(\mathrm{x}, \mathrm{t} ; \mathrm{x}^{\prime}, \mathrm{t}^{\prime}\right)$ is the Green's function tensor. The Green's function tensor is the contribution to the displacement in the $\hat{x}_{n}$ direction from a unidirectional unit-impulse in direction $\hat{x}_{p}$ (see Fig. 8(b)).

The integrals of Eq. (6) provide the total response due to the source distribution. In this case, the source is limited in the space $x^{\prime}$ and time $t$ '. Therefore, the integral is not calculated over the source region $\Omega$.

The use of the $\mathrm{g}\left(\mathrm{x}, \mathrm{t} ; \mathrm{x}^{\prime}, \mathrm{t}^{\prime}\right)$ provides a solution for a partial differential operator $\mathcal{L}(\mathrm{u}(\mathrm{x}, \mathrm{t}))$ with boundary conditions $\mathcal{B}(\mathrm{u}(\mathrm{x}, \mathrm{t}))$ in the range $\mathrm{x}_{\min }$ to $\mathrm{x}_{\max }$, described as $\mathrm{g}:\{\mathcal{L}(\mathrm{u}(\mathrm{x}, \mathrm{t}), \mathcal{B}(\mathrm{u}(\mathrm{x}, \mathrm{t}))$, $\left.\mathrm{u}(\mathrm{x}, \mathrm{t}),\left\{\mathrm{x}, \mathrm{x}_{\min }, \mathrm{x}_{\max }\right\}, \mathrm{t},\left\{\mathrm{x}^{\prime}, \mathrm{t}^{\prime}\right\}\right\}[15]$. To solve the nonhomogeneous (i.e. $\neq 0$ ) wave equation $[12,69]$ using $g$, the solution of $\mathcal{L}(u(x, t))$ as an one-dimensional $x$ equation of transversal body waves $\beta_{\mathrm{s}}[16]$ with unbounded, $\mathcal{B}=0$, the relation becomes $\mathrm{g}:\left\{\frac{\partial^{2} w(x, t)}{\partial x^{2}}-\frac{1}{\beta_{s}{ }^{2}} \frac{\partial^{2} w(x, t)}{\partial t^{2}}, \mathcal{B}=0\right.$, $\left.w(x, t),\{x,-\infty, \infty\}, t,\left\{x^{\prime}, t^{\prime}\right\}\right\}$, whit $\beta_{s}{ }^{2}=(\mu / \rho)^{1 / 2}=1 . \mu$ is the Lamé constant and $\rho$ is the material density.

$\mathrm{g}$ solution is:

where $\Theta\left(x, t, x^{\prime}, t^{\prime}\right)$ is the Heaviside theta step function, which is assumed as a displacement discontinuity [28]. $\Theta$ is a multidimensional function, which is 1 only if none of the $x, t, x^{\prime}, t^{\prime}$ are not positive. $|\cdot|$ is the modulus. 
390 Eq. (7) represents the solution of the wave equation-through $\Theta$ function. By substituting Eq. (7) 391 in Eq. (6) with $f\left(x^{\prime}, t^{\prime}\right)=1$, it is possible to plot the trend due to the amplification of the Green's 392 function $\mathrm{g}$ as shown in Fig.7.

394 In fact, the solution of Eq. (6) is a space and time convolution and the spatial part is two (or 395 three) dimensional, and that will affect the seismograms. However, this amplification quantifies 396 the physical nature of the seismic source. Therefore, a reduction it is not necessary.

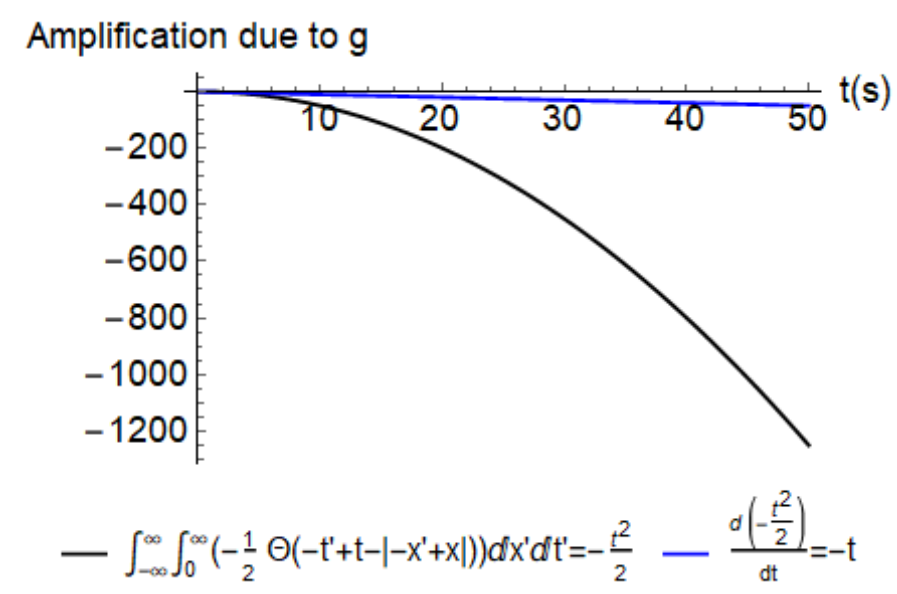

398 399

400

401

402

403

404

405

406

407

$408 \mathrm{f}\left(\mathrm{x}^{\prime}, \mathrm{t}^{\prime}\right)=\left\{\begin{array}{cc}\sum_{i=1}^{n} a_{h, i}\left(\sin \left(\omega_{i} t^{\prime}+\phi_{i}\right)+\cos \left(\omega_{i} x^{\prime}+\phi_{i}\right)\right) & \text { Random } \\ a_{h} \sin \left(x^{\prime}\right) e^{-t \prime} & \text { Impulsive } \\ a_{h}\left(\sin \left(x^{\prime}\right)+\cos \left(t^{\prime}\right)\right) & \text { Periodic } \\ a_{h}\left(x^{\prime}+t^{\prime}\right) & \text { Linear }\end{array}\right.$ 
410

411

412

413

414

415

416

417

418

419

420

421

422

423

424

425

426

427

428

429

430

431

432

433

434

435

436

437

438

439

440

441

442

443

where $a_{h}$ is the amplitude of the source function (latter described), $\omega_{i}$ is the circular frequency $\left(\omega_{\mathrm{i}}=2 \pi \mathrm{f}_{\mathrm{i}}\right), \phi_{\mathrm{i}}$ is a random phase between 0 and $2 \pi, \mathrm{n}$ is the number of summed simple harmonic components (here $\mathrm{n}=1500$ ).

Eq. (8) is expressed by four different types to individuate the characteristics of complicated ruptures, with a sine/cosine/exponential function that can represent the trend in time $t$ ' and space $x^{\prime}$, because the accelerations of the source are unknown. In this sense, Eq. (8) defines a seismic source in both deterministic and probabilistic form. It is important to note that, in this way, if there is consistency with the motion of a random energy propagation, there may not be consistency with the rupture.

\subsubsection{Hypocentre with punctual mass}

Eq. (7) does not represent a physical quantity; therefore, it is necessary to introduce it in Eq. (8). As shown in literature [11], the source function can be correlated by the Lamé constant (or shear modulus) $\mu$, which is related to the seismic moment by $\mathrm{M}_{0}=\mu \times \mathrm{A} \times \overline{\mathrm{u}}$, where $\mathrm{A}$ is the rupture area and $\overline{\mathrm{u}}$ is the average displacement $[3,13,72]$.

Also, in [11], Eq. (6) is expressed as the product of the EGF times an a-dimensional amplitude of $\mathrm{M}_{0}$, obtaining a EGF with the same units of $\mathrm{u}(\mathrm{x}, \mathrm{t})$. In an equivalent way, here it is introduced a hypocentre with an idealized punctual mass.

A new parameter is introduced in Eq. (8) in order to provide to Eq. (6) a physical quantity in terms of accelerations. From $M_{0}$, it is obtained an equivalent relationship $M_{0}=a_{h} \times M_{\mu} \times \bar{u}$, where $a_{h}$ is the acceleration at hypocentre and $M_{\mu}$ is called "supermassive hypocentre", expressed in $\mathrm{kg}$. In this sense $\mathrm{M}_{0}$ continues to be expressed as a force times a displacement, i.e. work.

The concept that allows to obtain this equivalent relationship is that the shear modulus $\mu$, calculated as a shear force divided by the area on which the force acts, is calculated as a mass times acceleration. The accumulations of static stresses released by faulting (i.e. static stresses drop) have been idealized as an inertial force along a infinity fault line $\left\{L^{\prime} \equiv x^{\prime} \mid x^{\prime}(-\infty, \infty)\right\}$. The correlation, at mathematical level, between $\mathrm{M}_{\mathrm{w}}$ and a mass has been already introduced in other studies $[20,70]$. 
445 Also, in his model, the fault is considered as linear. Therefore, $x^{\prime} \in \Omega$ in Eq. (5) becomes an 446 infinity line $-\infty<x^{\prime}<\infty$, as shown in Eq. (6). The solution of Eq. (6) demands this infinity 447 range, which could be justified by the fact that the considered $\mathrm{M}_{0}$ are very large (see Table 6) 448 and therefore the source dimensions are also very large. Moreover, the relationship between $\mathrm{M}_{0}$ 449 and $x^{\prime}$ is quasi-linear and tends to infinity as shown in literature $[11,29,71]$.

450

451

452

454 455 456

Therefore, the acceleration $a_{h}$ can be expressed as $a_{h}=M_{0} /\left(M_{\mu} \times \bar{u}\right) \approx M_{0} / M_{\mu}$ because both $M_{0}$ and $\mathrm{M}_{\mu}$ have a very large magnitude (e.g. $\sim 10^{20}$ ) with respect to $\overline{\mathrm{u}}$, which has a magnitude of meters. The objective is to estimate a unique parameter $M_{\mu}$ and $a_{h}$ knowing PGA and $M_{0}$. This is possible through the plotting of the Eq. (6) from hypocentre to site. In this way, two constant values are used like the approach shown in literature [27].

The model described in Fig. 8(a) is valid under the following hypotheses.

1. Epicentre and site points must be placed inside of a unique ZS so that all parameters retrieved from seismogenic zones are valid.

2. Hypocentre point must be at a depth $\Delta<30 \mathrm{~km}$ because ZS are calculated up to this depth. In this way, the probability $\mathrm{P}\left[\mathrm{M}_{\mathrm{w}}>\mu_{\mathrm{w}, \mathrm{i}}\right]$ at the surface is the same at any point $\mathrm{P}\left[\mathrm{M}_{\mathrm{w}}>\mu_{\mathrm{w}, \mathrm{i}}\right]$ at the wave path.

3. The source geometry must be modelled as linear. In this way Eq. (2) and Eq. (6) are valid.

4. Data of an earthquake registration must be taken from a station at a studied ZS. Both methods are correlated by $\mathrm{M}_{\mathrm{w}}$, which is retrieved from ZS and database, and then it is inserted in EGF.

(

. 


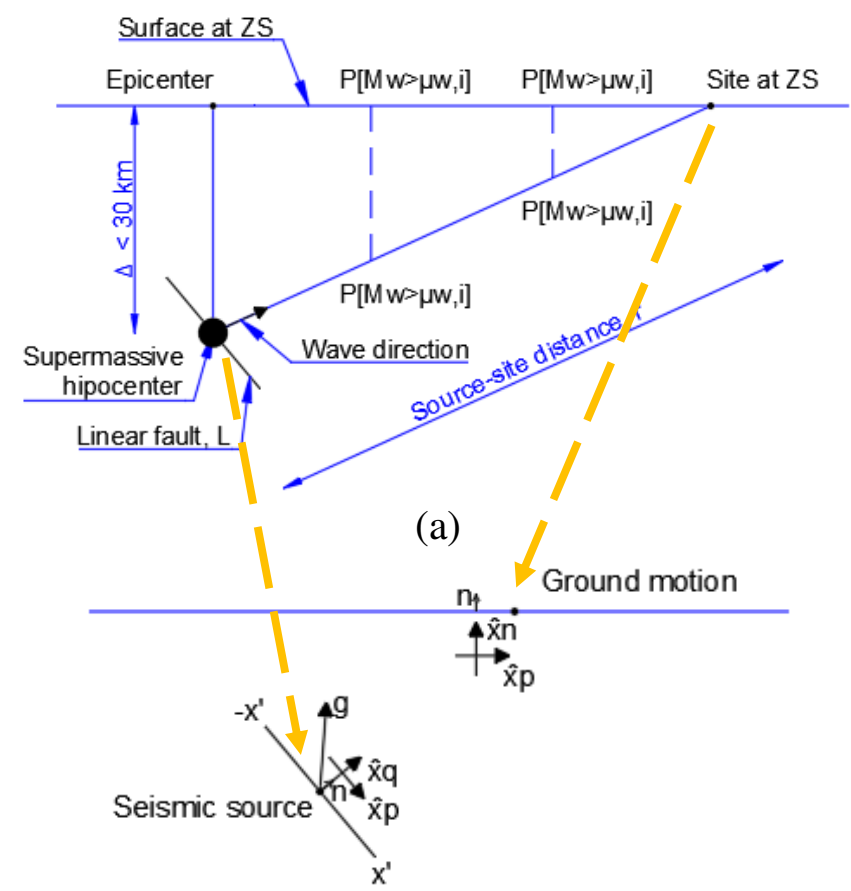

(b)

479 Figure 8. New model for PSHA + EGF (a); vectors and tensors at seismic source and ground 480 motion (b).

481

\section{Results and discussions}

\section{$483 \quad 4.1 \quad$ Return periods by PSHA}

As abovementioned, a ZS is characterized by seismic parameters (a-value, b-value, $\lambda_{c}$ ), which are obtained from a group of events that are homogeneous and independents of each other. This indicates that for the same ZS is possible to establish a unique period, $\mathrm{T}_{\mathrm{e}}$, in which these seismic parameters are maintained.

The hypothesis is that the seismogenic context for each ZS will be reasonably the same since the tectonic phenomena change during very long periods. However, the seismic parameters can suffer little variations because they are very sensible to the amount of data in the database. In

493 this sense, there is a proposed a unique return period $\mathrm{T}_{\mathrm{e}}$ consistent to the real sequence of events accounting for the seismogenic parameters. The idea is not to eliminate the concept of the return period but to separate it from the 497 calculation of acceleration, as a safety factor, given that, nowadays, specific studies that provide 498 more reliable inputs are available. This aspect questions the use of extremely large return 
499 periods, $\mathrm{T}_{\mathrm{r}}>1000$ years, to increase seismic acceleration. Therefore, in this sense, via this 500 methodology, the third problem described in introduction could be overcome.

501

502 Fig. 9 shows the results in a graphic $\mathrm{M}_{\mathrm{w}}$ vs. year for three seismogenic zones (i.e. ZS 7, ZS 9, 503 ZS 10). The dashed line represents the moving average of the events. The return period $\mathrm{T}_{\mathrm{e}}$ refers 504 to the maximum return period for which the characteristics of the seismicity maintains constant, 505 whereas the return period $\mathrm{T}_{\mu \mathrm{w}}$ (interval of the vertical lines) is calculated by Eq. (4).

506

507

508

509

510

511

512

513

514

515

516

517

518

519

520

521

522

523

524

525

526

527

528

529

530

531 


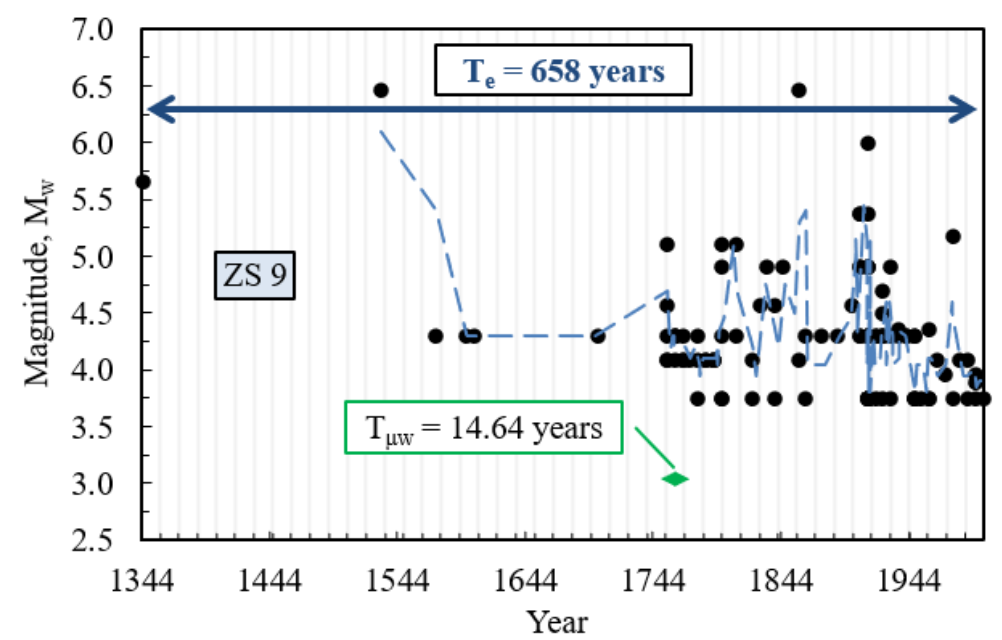

(a)

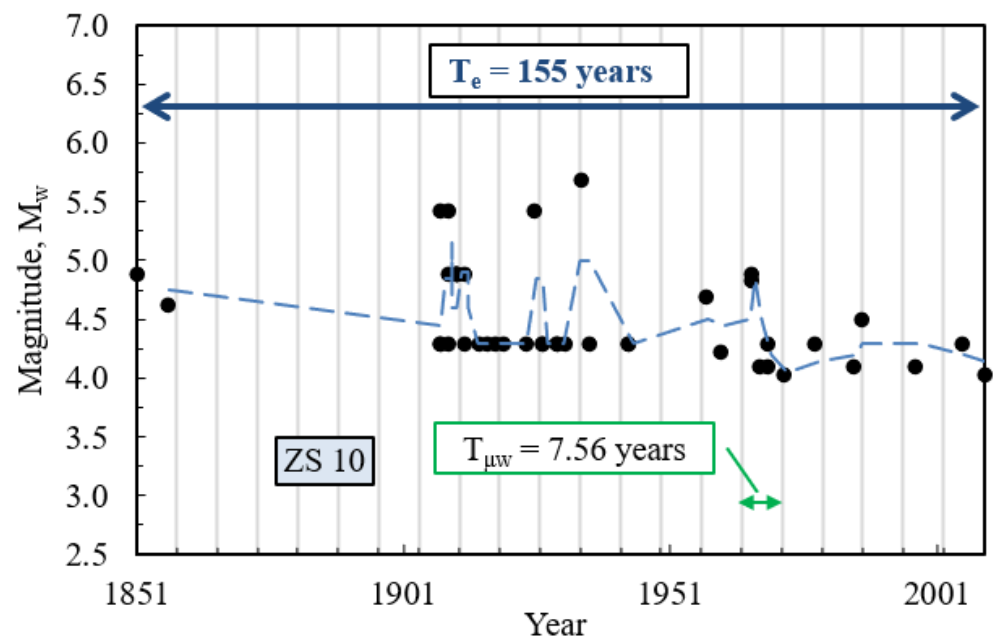

(b)

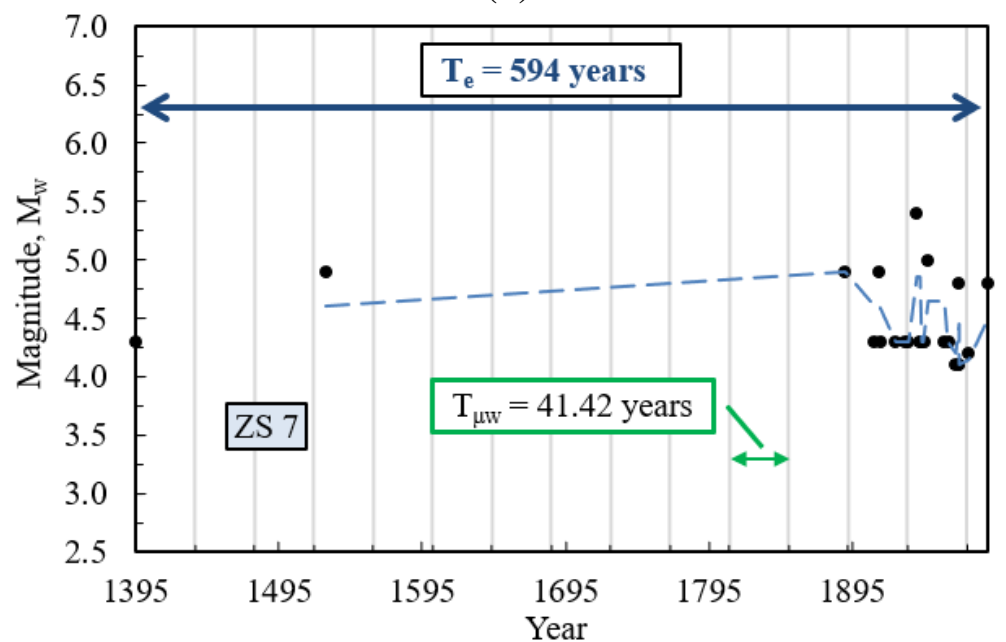

(c)

534 Figure 9. $M_{w}$ vs. year and return periods for the ZS 9 (a), ZS 10 (b), ZS 7 (c). 
In Fig. 9(a) there are 107 events in a period 1344-2002 years with a mean value $\mu_{\mathrm{w}}=4$.3. It is possible to see that in a period 1760-2002 years the sequence of the events is more consistent to the calculated $\mathrm{T}_{\mu \mathrm{w}}$ (in this period the moving average, the dashed line, oscillates more).

$\mathrm{T}_{\mu \mathrm{w}}$ is assumed as valid for all period. This because, as known, very old events are not recorded. However, geophysicists that have defined this seismogenic zone have considered these events as valid events that define the ZS 9. These considerations are also valid for Fig. 9(b) and Fig. $5439(\mathrm{c})$.

Under these considerations, if $T_{\mu w} \leq T_{r} \leq T_{e}$, it is possible to assume $T_{r}$, provided by literature $\left(T_{r}=475\right.$ years), for any type of structures, because this period is rightly framed in a same seismogenic context. If this range is not verified, a $T_{r} \geq 475$ year loses meaning.

In this way, the importance factor is $\gamma_{\mathrm{I}}=1.0$. It is defined as $\gamma_{\mathrm{I}} \approx\left(\mathrm{T}_{\mathrm{r}} / \mathrm{T}_{\mathrm{L}}\right)^{-1 / k}$, where $\mathrm{T}_{\mathrm{L}}$ is the return period of a requirement specific level, $\mathrm{k}$ is a factor that depend on the seismicity, which is generally of the order of 3.0, like the a-value (see Table 4) [8,50].

Table 7 resumes the results. It is possible to conclude that for these three seismogenic zones a $\mathrm{T}_{\mathrm{r}}$ that should be used for all type of structures, independently of their importance, is 475 years.

Table 7. Summary of results.

\begin{tabular}{cccccc}
\hline Event & $\mathbf{Z S}$ & $\boldsymbol{\mu}_{\mathrm{w}}$ & $\mathbf{T}_{\boldsymbol{\mu w}}($ year) & $\mathbf{T}_{\mathbf{e}}(\mathbf{y e a r})$ & $\mathbf{T}_{\mathbf{r}, \max }(\mathbf{y e a r})$ \\
\hline Évora, 2018 & 10 & 4.3 & 7.56 & 155.0 & \\
Leiria, 1999 & 7 & 4.3 & 41.42 & 594.0 & $475.0^{\mathrm{a}}$ \\
Lisbon, 2000 & 9 & 4.3 & 14.64 & 658.0 & \\
Lisbon, 2017 & & & & & \\
\hline
\end{tabular}

${ }^{a}$ It represents the maximum $T_{\mathrm{r}}$ that could be adopted for designing of any type of structure placed in a specific ZS.

The results for Lisbon are consistent with the literature [64] where the probability of exceedance 562 of 475 years is less than $1 \%$ for the magnitude 3.5-6.5. This confirms that using a period longer than 475 years overestimates the seismic input. 
565 It is important to note that the offshore seismicity has not been considered, which affects the 566 seismicity of these studied places as shown in literature [64]. This is because by considering 567 the offshore zones, e.g. ZS 50, where the great 1755 Lisbon earthquake was generated, the seismicity increases as commented also in [67]. The idea in this work is not to consider very distant zones to estimate seismic inputs because (i) there are no attenuation equations for Portugal that can well calibrate the results at these distances (see Table 1); (ii) the adopted model follows Fig. 8(a)

These results should separate the PGA of $\gamma_{\mathrm{I}}$, which relates to the consequences of a structural failure. Buildings are classified in classes, depending on the consequences of collapse for human life, public safety, civil protection and thus social and economic consequences in the post-earthquake period $[7,8]$.

The logic to divide the performance requirements in no-collapse and damage is fundamental, but it should not motivate an increase in seismic input. It should be associated to the completeness of modelling, deepening of seismic analyses (object of this study), design and detailing of primary and secondary elements and connections.

An overestimation of $\gamma_{I}$ leads to an overdesigning of, for instance, small structures considered as important, because the design inertial force can reach very high values. Moreover, in many cases, the lack of attention for designing of small/medium structures makes using a high input value quickly solve the security problem. For this reason, it is useful to separate the acceleration from $\gamma_{\mathrm{I}}$, but focusing more on the modelling and detailing.

\subsection{Ground motions by EGFs}

Fig. 10 shows the source function $f\left(x^{\prime}, t^{\prime}\right)$ defined by Eq. (8) in $2 \mathrm{D}$ and $3 \mathrm{D}$ for four cases: random, impulsive, periodic, linear. The $2 \mathrm{D}$ trend ( $\mathrm{f} v \mathrm{vs} . \mathrm{t}^{\prime}$ ) is a transversal section of the $3 \mathrm{D}$ trend at $x^{\prime}=0$, except for the impulsive function that is calculated at $x^{\prime}=1.5 \mathrm{~m}$. Used data refer to the Lisbon 2000 event. 
$2 \mathrm{D}\left(\right.$ at $\mathrm{x}^{\prime}=0 \mathrm{~m}$ for random, periodic, linear; at $\mathrm{x}^{\prime}=1.5 \mathrm{~m}$ for impulsive)

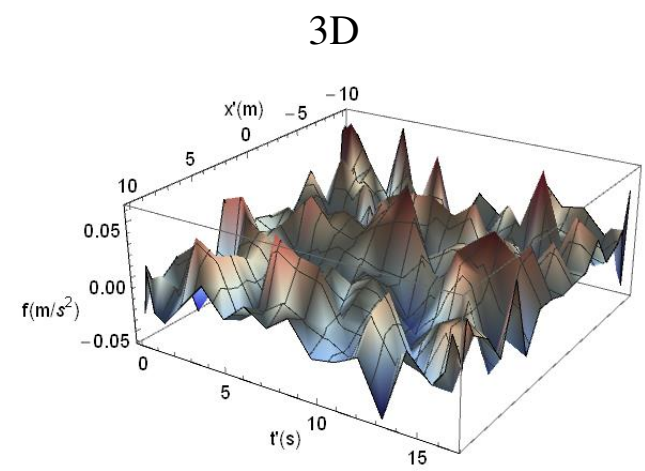

Random source function (a)
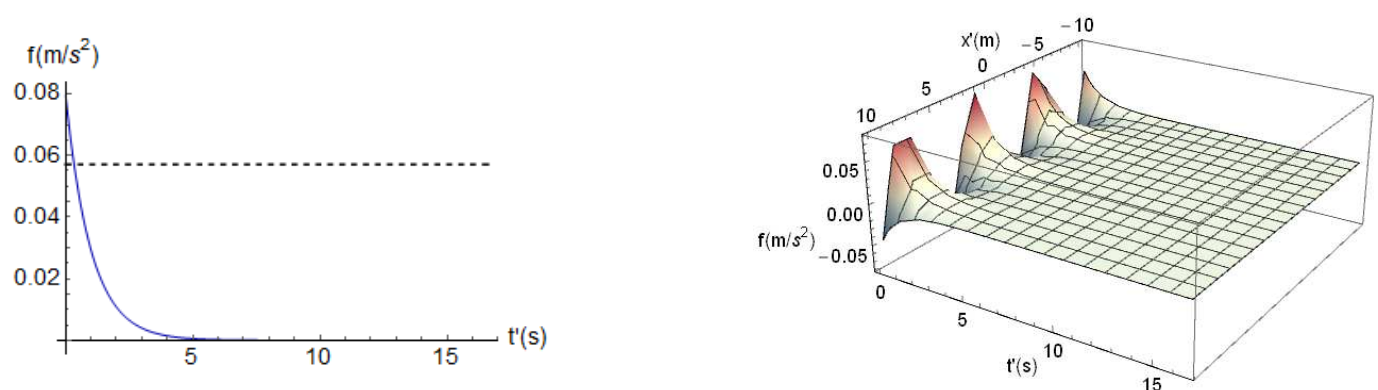

Impulsive source function (b)
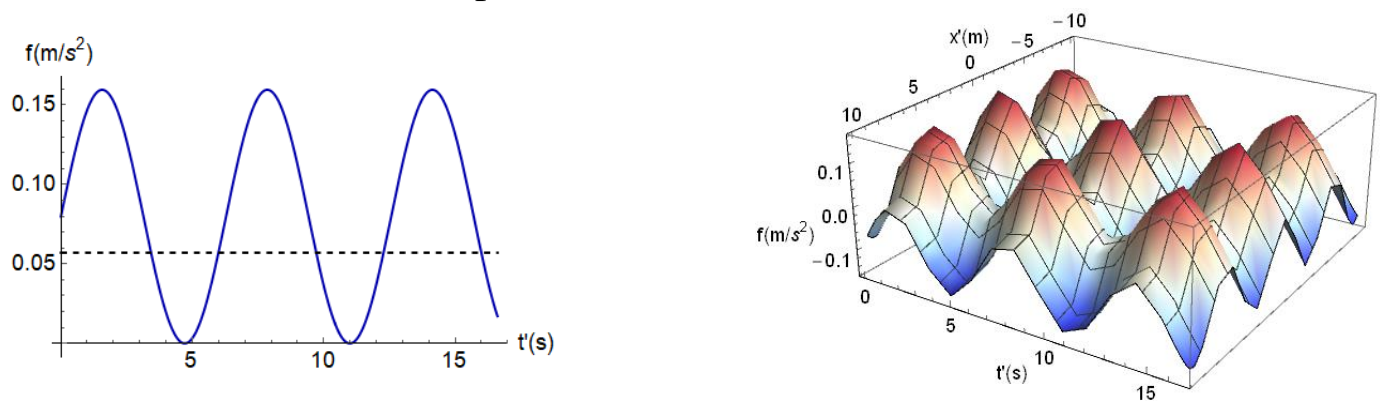

Periodic source function (c)
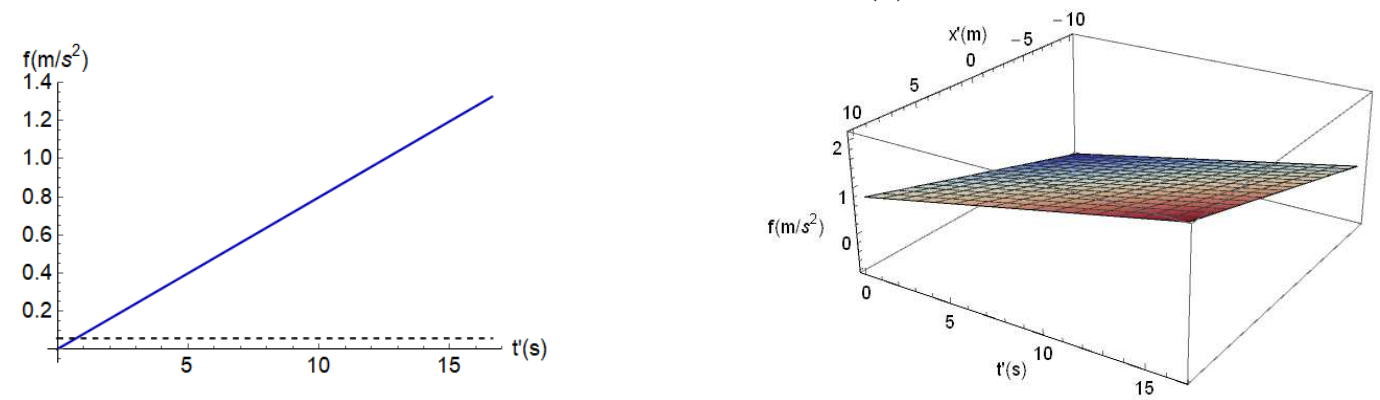

Linear source function $(\mathrm{d})$

600 Figure 10. Source function (see Eq. (8)) expressed by a random (a), impulsive (b), periodic (c), 601 linear (d) function in 2D/3D. Used data refer to Lisbon 2000 event. Horizontal dashed line 602 represents the PGA value (i.e. $0.057 \mathrm{~m} / \mathrm{s}^{2}$ ). 
604 The source function, expressed by four types of functions, represent an artificial acceleration

605 [26] of the soil at hypocentre. These functions are plotted in the significant duration $\mathrm{T}_{\mathrm{s}}$, i.e. $0 \leq$ $606 \mathrm{t}^{\prime} \leq \mathrm{T}_{\mathrm{s}}$ (see Table 6), whereas the spatial variable $\mathrm{x}^{\prime}$ is plotted between $10 \leq \mathrm{x}^{\prime} \leq 10 \mathrm{~m}$.

607

608 In 3D view it is possible to see that the released energy comes from a line where the acceleration 609 assumes a value of $\mathrm{f} \neq 0$ at $\mathrm{t}^{\prime}=0$.

610

611 Figure 11 shows the results for the Lisbon 2000 event in terms of displacements of the ground 612 motion computed by using Eq. (6), then, by deriving Eq. (6) in the time t, velocities and accelerations are obtained.

614

615 The impulsive source function is used as reference, i.e. the parameters $M_{\mu}$ and $a_{h}$ are calibrated 616 considering $(\ddot{\mathrm{u}}(\mathrm{x}, \mathrm{t})-\mathrm{PGA}) \approx 0$ under an impulsive source function. Because an impulsive 617 function is consistent to the physical process described in Eq. (6). Therefore, the amplitude $a_{h}$ 618 is calculated iteratively from registered PGA and $\mathrm{M}_{0}$ for each event. In function of this 619 calibration, other values of $\ddot{\mathrm{u}}(\mathrm{x}, \mathrm{t})$ are estimated. Thus, it is possible to note what source function 620 well estimates the $\ddot{\mathrm{u}}(\mathrm{x}, \mathrm{t})$.

621

Lisbon, 2000
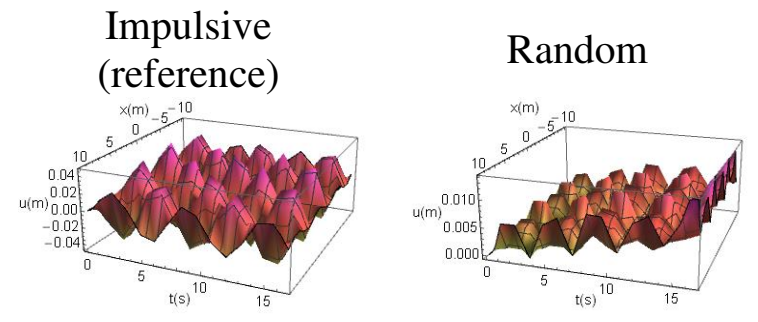

Periodic Linear

Displacements (a)
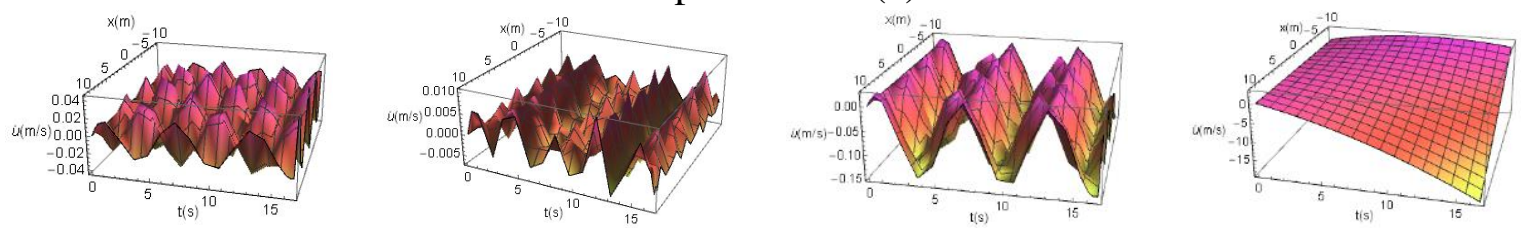

Velocities (b)
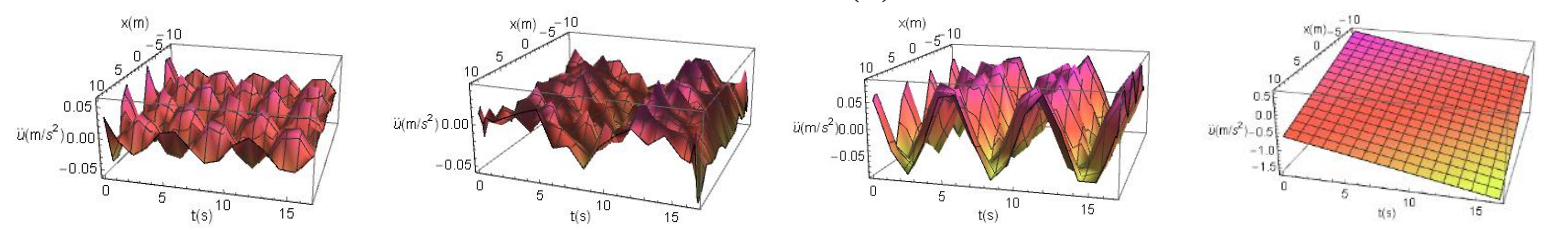

Accelerations (c)

622 Figure 11. Solutions in terms of displacements (a), velocities (b), accelerations (c) of the ground 623 motion for 2000 Lisbon earthquake. 
625 During the integrations, the values of the ground displacements assume ever larger values due 626 to the strong influence of the Green's function g, expressed in Eq. (7), that assumes exponential 627 values in function of the time $\mathrm{t}$ (see Fig. 7). This function is predominant with respect the source 628 functions expressed by Eq. (8). In fact, in the velocities and accelerations of the ground, it is 629 possible to see that the trend follows always the trend of the artificial accelerograms, because 630 the influence of the Green's function is weaker.

631

632 Figs. 12-14 show the ground accelerations for the other three considered events.

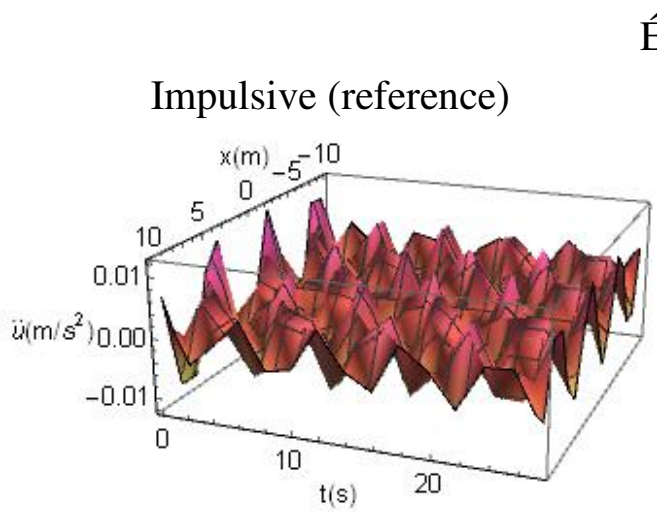

Periodic

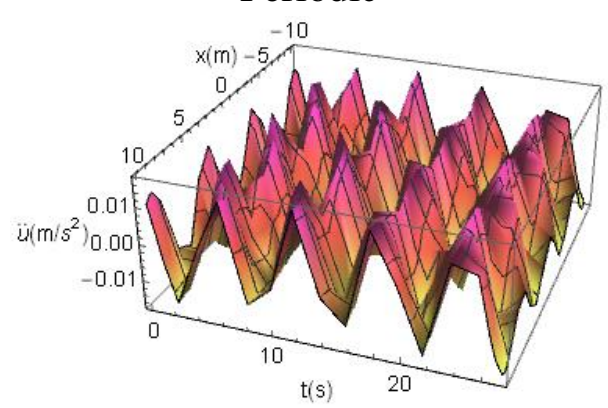

Évora, 2018

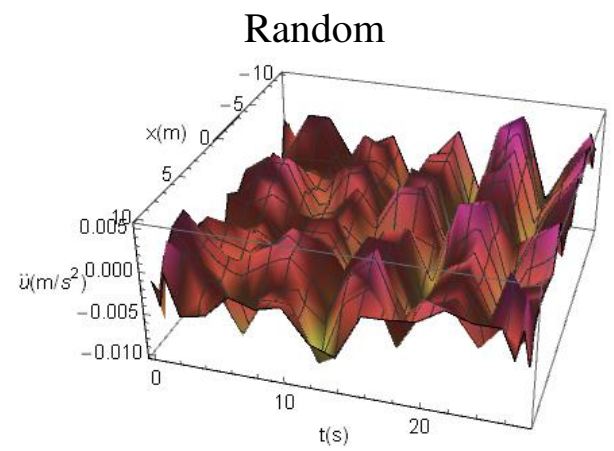

Linear

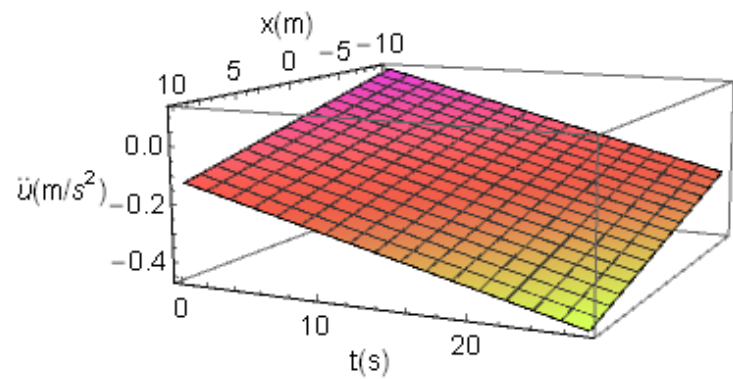

634 Figure 12. Solutions in terms of accelerations of the ground motion for 2018 Évora earthquake. 635 


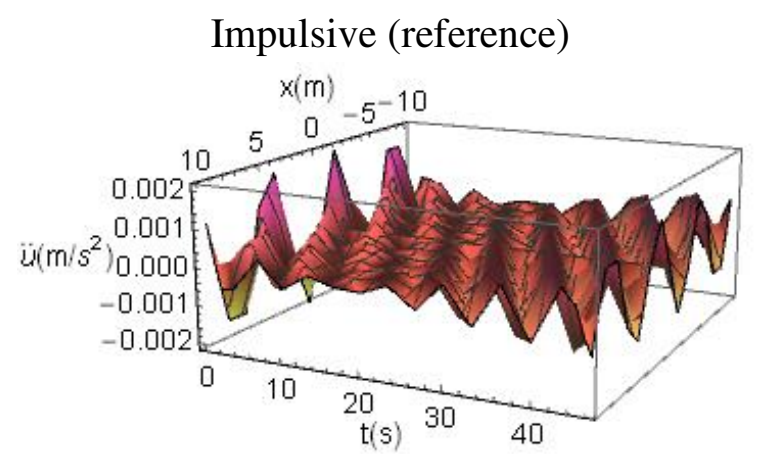

Periodic

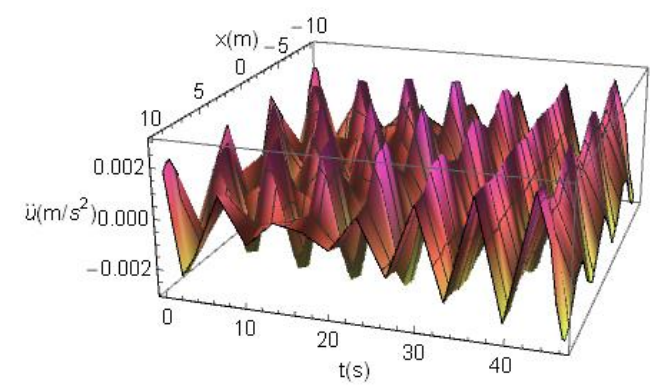

Random

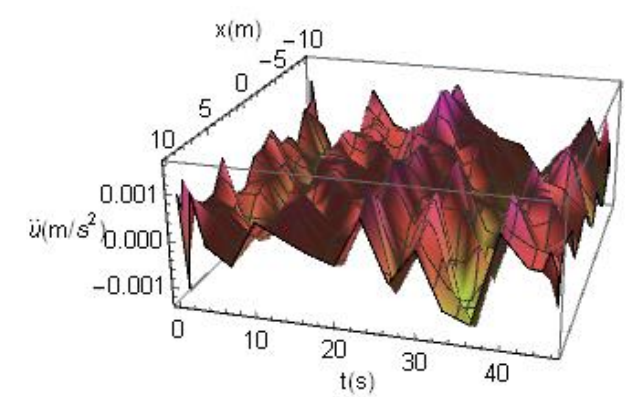

Linear

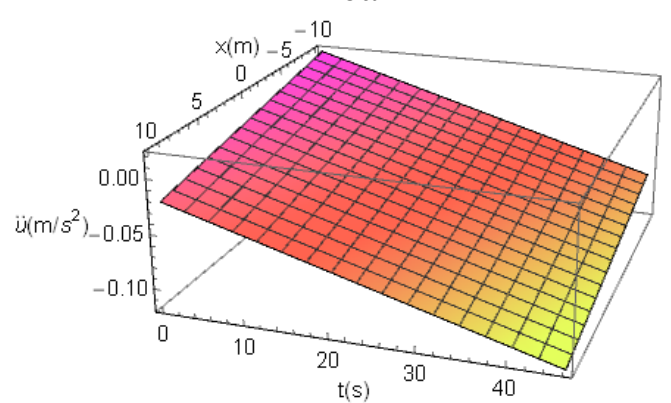

645 Figure 13. Solutions in terms of accelerations of the ground motion for 2017 Lisbon earthquake. 646

Leiria, 1999

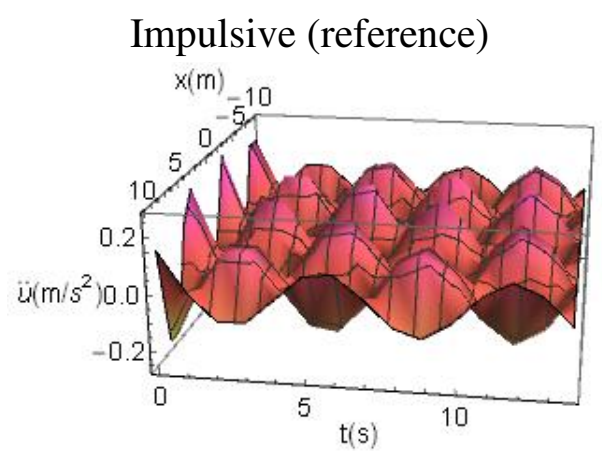

Periodic

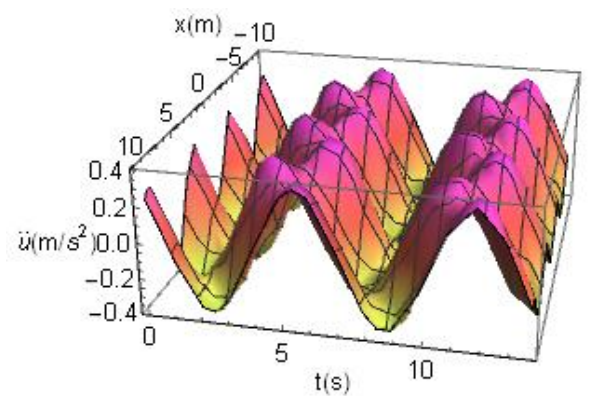

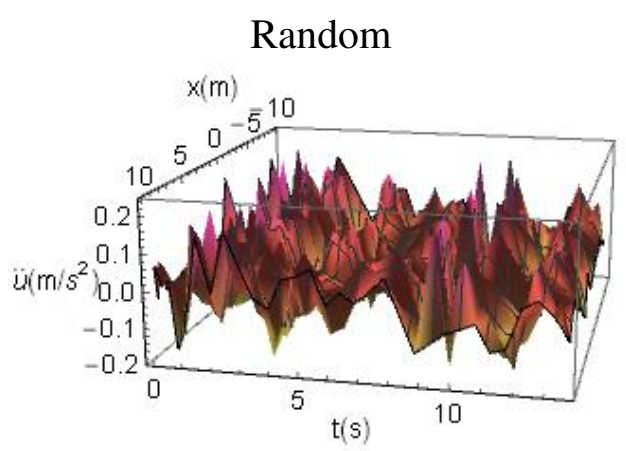

Linear

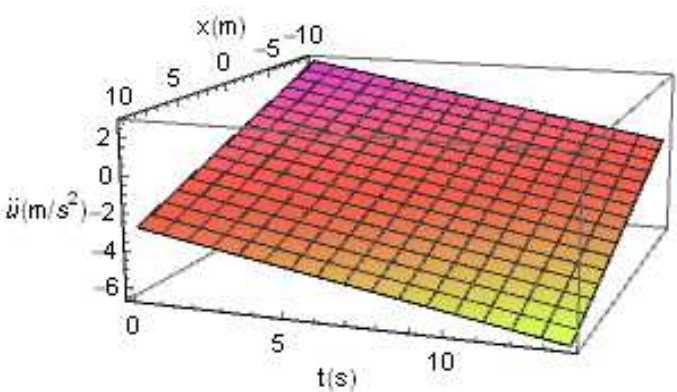

647 Figure 14. Solutions in terms of accelerations of the ground motion for 1999 Leiria earthquake.

649 Fig. 15 shows the relative error, for the four events, expressed in percentage (\%) calculated as:

650 (calculated value - registered value)/calculated value. The registered values are shown in Table 
651 6. In this way it is possible to estimate the contributions of the different source functions for 652 PGD, PGV, PGA.

653

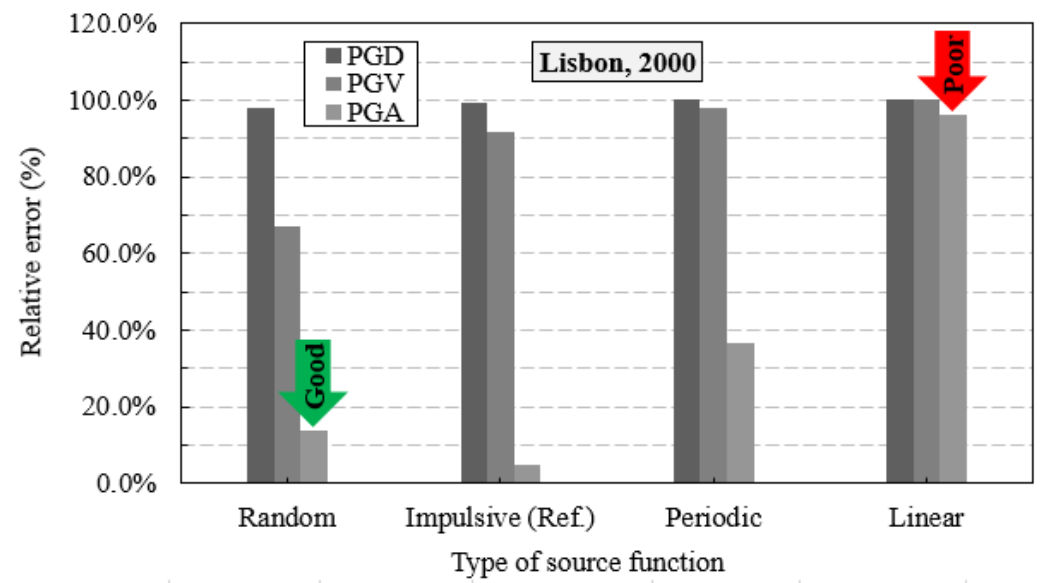

(a)

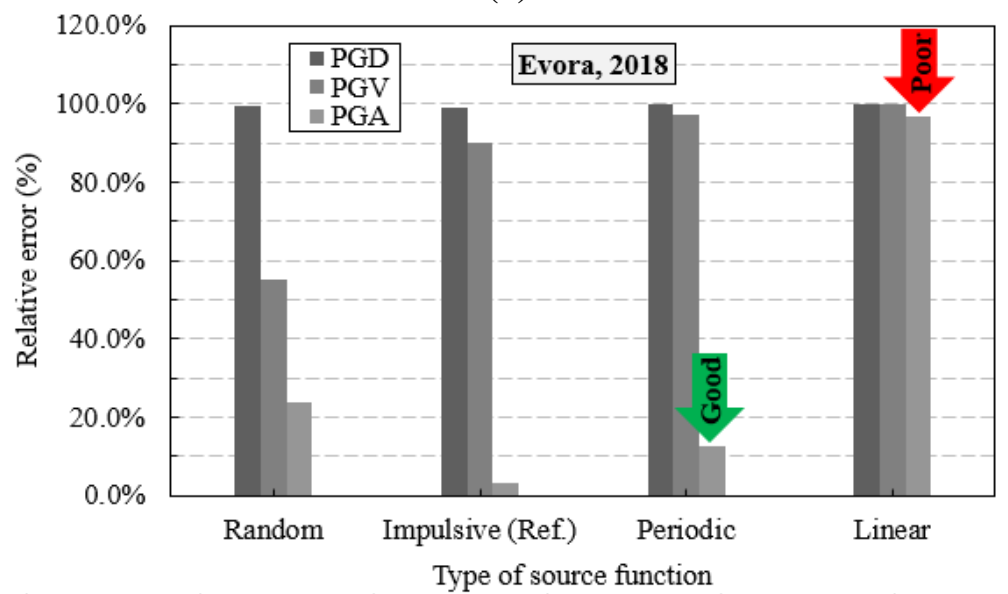

(b)

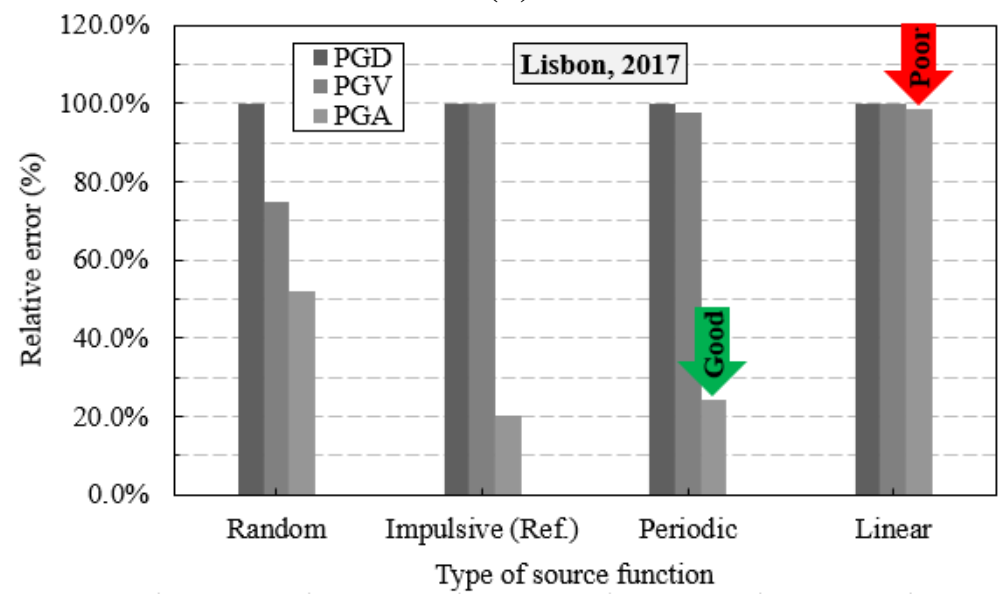

(c) 


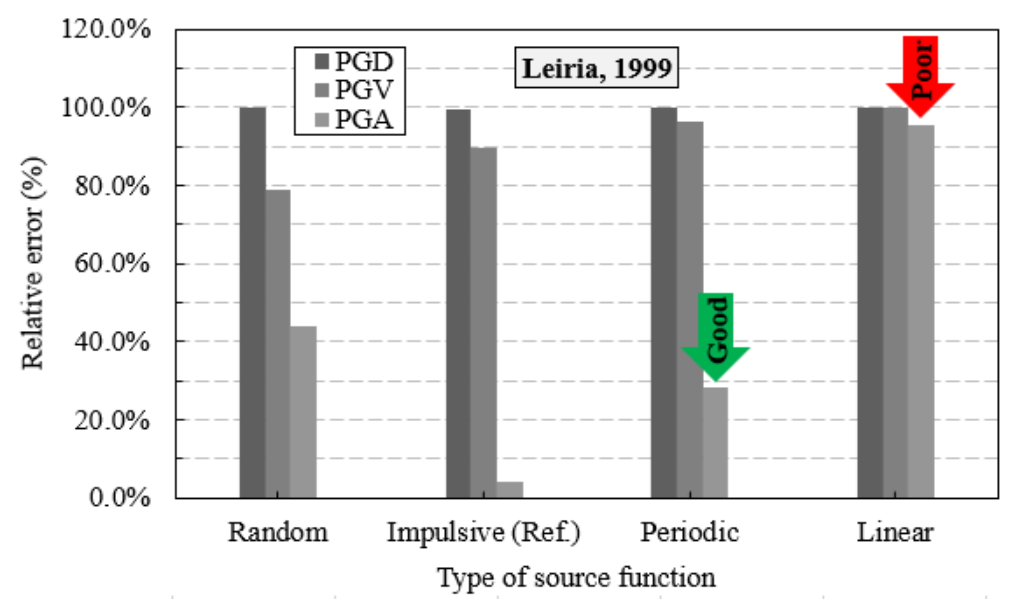

(d)

654 Figure 15. Relative error of each type of source for the 2000 Lisbon event (a), the 2018 Evora 655 event (b), the 2017 Lisbon event (c), the 1999 Leiria event (d),

657 In Fig.15 it is possible to see that for the values of PGD and PGV it is difficult to obtain a good 658 result due to the amplification already mentioned and shown in Fig. 7. In fact, this model is 659 applicable to estimate the PGA because the amplitude $a_{h}$ in Eq. (8) is introduced for this scope.

661 For the PGA, it is possible to see that the source function expressed by a random and periodic 662 function provide good results. In particular, the periodic function provides the best results with 663 a mean relative error for PGA of $21 \%$. Due to the stochastic nature of the random function, in 664 some case the results are good (Fig. 15(a)) whereas in other cases they are not (Fig. 15(b)-(c)665 (d)). By using a linear function, the PGA values are poor.

666

667 Table 8 shows the values of the parameters introduced in this analysis, i.e. $a_{h}$ and $M_{\mu}$, which 668 are correlated by $\mathrm{a}_{\mathrm{h}} \approx \mathrm{M}_{0} / \mathrm{M}_{\mu}$.

669

670 Table 8. Values of $\mathrm{a}_{\mathrm{h}}$ and $\mathrm{M}_{\mu}$.

\begin{tabular}{ccccc}
\hline & Évora, 2018 & Leiria, 1999 & Lisbon, 2000 & Lisbon, 2017 \\
\hline $\mathrm{a}_{\mathrm{h}}\left(\mathrm{m} / \mathrm{s}^{2}\right)$ & 0.0124 & 0.276 & 0.0627 & 0.0021 \\
$\mathrm{M}_{\mu}(\mathrm{kg})$ & $1.20 \times 10^{23}$ & $5.03 \times 10^{23}$ & $2.07 \times 10^{23}$ & $1.81 \times 10^{26}$ \\
\hline
\end{tabular}

672 The station location that registers the signals can be very distance to the epicentre. In many 673 cases, this distance is larger than the radius of the ZS, and, therefore, the relation between the 674 parameters of the PSHA and the parameters of the seismic source are not compatible (see Fig. 675 4). However, this problem also exists for the traditional PSHA by using attenuation equations. 
676 In fact, when more ZSs are considered to develop a unique analysis, the mean parameters of

677 ZSs are used. In this way, the mean of b-values for several ZSs are calculated despite the fact 678 that the adopted attenuation equation is calibrated for a unique homogenous mechanism fault, 679 i.e. for a unique ZS [30].

680

681 The model described in Fig. 8, must be applied in an area that corresponds to a unique ZS. 682 Therefore, as shown in Fig. 4, rigorously only where the results of the 2000 Lisbon earthquake 683 (Fig. 11) would be valid. However, mathematically, the method would continue to be also valid 684 for other events.

685

\section{Conclusions}

687

688 This paper combines the PSHA with EGFs through $\mathrm{M}_{\mathrm{w}}$ describing the source function via 689 random, impulsive, periodic, linear function. Some parameters of ZSs for Portugal and specific 690 return periods have been estimated.

691

692 The main conclusions are:

693

694 1. A comparison between the parameters of existing seismogenic zones (Share, Ersta, EC8, 695 ZESIS) and other parameters estimated in this paper has been carried out. In this sense, it has 696 been demonstrated that the epistemic uncertainties correlated to the models are still very 697 changeable. Table 3 shows the difference of the main parameters for PSHA (i.e. b-value), which can contribute to reduce the gap of the various models.

699

2. An overestimation of $\gamma_{\mathrm{I}}$ leads to an overdesigning of, for instance, small structures considered as important, because the design inertial force can reach very high values with a small increasing of $\gamma_{\mathrm{I}}$. In many cases, for small/medium structures, the use of a high input value "resolves" the security problem neglecting an attention for designing. For this reason, it is useful to separate the PGA from $\gamma_{I}$ as shown in Table 7. For important small structures it will be essential focusing more on the modelling and detailing. 3. A new analytical approach to correlate PSHA with EGFs has been proposed. The key parameter for this correlation is $\mathrm{M}_{\mathrm{w}}$, which is estimated by PSHA and introduced in EGFs by 
$709 \mathrm{M}_{0}$ through relationship $\mathrm{a}_{\mathrm{h}} \approx \mathrm{M}_{0} / \mathrm{M}_{\mu}$. Results are shown in Table 8 . The model is valid under 710 conditions shown in the Fig. 8.

712 4. Four types of source functions have been studied: random, impulsive, periodic, linear. This 713 because a priori the source accelerations are not known. Results show that the periodic function 714 render better results. The relative error between the calculated and registered value is $12-36 \%$. 715 However, for PGA, a source function described by random function has a good calibration.

\section{Conflict of interest}

None.

\section{Acknowledgements}

The first author thanks the Itecons Institute, Coimbra, Portugal, for the Wolfram Mathematica license, and University of Coimbra (UC), Portugal, to pay authorship dues (when applicable) to completely download all papers in references. The first author also thanks Project Scientist Dr. Lawrence Hutchings (https://eesa.lbl.gov/profiles/lawrence-j-hutchings/), expert in seismology, for its constructive comments and suggestions, which helped to improve this paper. The second author acknowledges support by CNPq and FAPESP, both Brazilian research funding agencies.

\section{Annex}

733 The inhomogeneous (i.e. $\neq 0$ ) wave equations in one dimension for a function $\mathrm{w}(\mathrm{x}, \mathrm{t})$ is, for $-\infty$ $734<\mathrm{x}<\infty, \mathrm{t}>0$, given by (the process is retrieved from [18] and adapted to this study):

$736 \quad \frac{\partial^{2} w(x, t)}{\partial x^{2}}-\frac{1}{\beta_{s}^{2}} \frac{\partial^{2} w(x, t)}{\partial t^{2}}=h(x, t)$

738 for some given function $\mathrm{h}(\mathrm{x}, \mathrm{t})$.

739 The Green's function $\mathrm{g}\left(\mathrm{x}, \mathrm{t} ; \mathrm{x}^{\prime}, \mathrm{t}^{\prime}\right)$, by the Dirac delta function $\delta$ [17], associated with Eq. (A1) 740 satisfies 
$742 \frac{\partial^{2} g\left(x, t ; x^{\prime}, t^{\prime}\right)}{\partial x^{2}}-\frac{1}{\beta_{s}{ }^{2}} \frac{\partial^{2} g\left(x, t ; x^{\prime}, t^{\prime}\right)}{\partial t^{2}}=\delta\left(x-x^{\prime}\right) \delta\left(t-t^{\prime}\right)$

743

744 By using a Fourier's transform, it is obtained:

745

$746 \frac{1}{\beta_{s}{ }^{2}} \frac{\partial^{2} G\left(x, t ; x^{\prime}, t^{\prime}\right)}{\partial t^{2}}+x^{2} G\left(x, t ; x^{\prime}, t^{\prime}\right)=\delta\left(t-t^{\prime}\right) e^{i x x^{\prime}}$

747

748 Let $\mathrm{G}\left(\mathrm{x}, \mathrm{t} ; \mathrm{x}^{\prime}, \mathrm{t}^{\prime}\right)=\exp \left(\mathrm{ixx} \mathrm{x}^{\prime}\right) \mathrm{r}(\mathrm{x}, \mathrm{t})$, a function $\mathrm{r}(\mathrm{x}, \mathrm{t})$,

749

$750 \quad \frac{1}{\beta_{s}^{2}} \frac{\partial^{2} r(x, t)}{\partial t^{2}}+x^{2} r(x, t)=\delta\left(t-t^{\prime}\right)$

751

752 therefore

753

$754 \quad \frac{1}{\beta_{s}{ }^{2}} \frac{\partial^{2} r(x, t)}{\partial\left(t-t^{\prime}\right)^{2}}=-x^{2} r(x, t)$

755

756 which has solutions $r(x, t)=A(t) \sin \left[x\left(t-t^{\prime}\right)\right]$, with $A(t)=\int \delta\left(t-t^{\prime}\right) / x d t$, is an amplitude of sine 757 function.

758 By using the fact that $\int \delta\left(t-t^{\prime}\right) d t=\Theta\left(t-t^{\prime}\right), r(x, t)$ is

759

$760 \quad r(x, t)=\frac{\sin \left[x\left(t-t^{\prime}\right)\right] \Theta\left(t-t^{\prime}\right)}{x}$

761

762 therefore, considering the equivalence between Eq. (A3) and Eq. (A4),

763

$764 G\left(x, t ; x^{\prime}, t^{\prime}\right)=\frac{e^{i x x^{\prime}} \sin \left[x\left(t-t^{\prime}\right)\right] \Theta\left(t-t^{\prime}\right)}{x}$

765

766 Thus, it is shown that the Fourier's transform in $\mathrm{x}$ of the Green's function, $\mathrm{G}\left(\mathrm{x}, \mathrm{t} ; \mathrm{x}^{\prime}, \mathrm{t}^{\prime}\right)=\mathrm{F}(\mathrm{g}(\mathrm{x}$,

767 t; $\left.x^{\prime}, t^{\prime}\right)$ ), is given by Eq. (A7),

768

769 Finally, by taking the inverse of Fourier's transform 
$g\left(x, t ; x^{\prime}, t^{\prime}\right)=F^{-1}\left[G\left(x, t ; x^{\prime}, t^{\prime}\right)\right]=\frac{1}{2 \pi} \int_{-\infty}^{\infty} G\left(x, t ; \mathrm{x}^{\prime}, t^{\prime}\right) e^{-i x^{2}} d x=$

772

$\int_{-\infty}^{\infty} \frac{\Theta\left(t-t^{\prime}\right) \sin \left[x\left(t-t^{\prime}\right)\right] e^{i x(x \prime-x)}}{2 \pi x} d x$

773

774 and by using two general identities (i) $2 \sin (\alpha)(\cos (\beta)+\sin (\beta))=\sin (\alpha-\beta)+\sin (\alpha+\beta)+\cos (\alpha$

$-\beta)-\cos (\alpha+\beta)$ and (ii) $\mathrm{e}^{\mathrm{i} \alpha}=\cos (\alpha)+\mathrm{i} \operatorname{sen}(\alpha)$, it is obtained

776

777

$g\left(x, t ; x^{\prime}, t^{\prime}\right)=\frac{\Theta\left(t-t^{\prime}\right)}{4 \pi} \int_{-\infty}^{\infty}\left(\frac{\sin \left[x\left(t-t^{\prime}+x^{\prime}-x\right)\right]}{x}+\frac{\sin \left[x\left(t-t^{\prime}-x^{\prime}+x\right)\right]}{x}+i \frac{\cos \left[x\left(t-t^{\prime}+x^{\prime}-x\right)\right]}{x}+\right.$

$\left.778 \quad i \frac{\cos \left[x\left(t-t^{\prime}-x^{\prime}+x\right)\right]}{x}\right) d x$

779

780 Neglecting the imaginary part, knowing that $\int_{-\infty}^{\infty} \frac{\sin (\alpha)}{\alpha} d \alpha=\pi$ and introducing the sign

781 function $\operatorname{asgn}(\alpha)=-1,0,1$ for $\alpha<0, \alpha=0, \alpha>0$, respectively, Eq. (A9) is:

782

783

$g\left(x, t ; x^{\prime}, t^{\prime}\right)=\frac{\Theta\left(t-t^{\prime}\right)}{4 \pi} \pi\left(\operatorname{sgn}\left(t-t^{\prime}+x^{\prime}-x\right)+\operatorname{sgn}\left(t-\mathrm{t}^{\prime}-x^{\prime}+x\right)\right)$

784

785

that, considering $\operatorname{sgn}(\alpha) \approx 2 \Theta(\alpha)$, can be written as

786

787

$\left.\mathrm{g}\left(\mathrm{x}, \mathrm{t} ; \mathrm{x}^{\prime}, \mathrm{t}^{\prime}\right)=-\frac{1}{2} \Theta\left[\left(-t^{\prime}+t\right)-\left|-x^{\prime}+x\right|\right)\right]$

788

789

that is Eq. (7).

790

791

Note that Eq. (7) has a similar form with respect to the general solution of Eq. (A1) with h(x.t)

$792=0, \beta_{\mathrm{s}}=1$ and unbounded condition $\mathrm{B}=0$, that is $\mathrm{w}(\mathrm{x}, \mathrm{t})=\mathrm{c}_{1}(\mathrm{t}-\mathrm{x})+\mathrm{c}_{2}(\mathrm{t}+\mathrm{x})$, where $\mathrm{c}_{1}$ and $793 \mathrm{c}_{2}$ are two arbitrary differential equations.

\section{References}

796

797 [1] Zhan Z (2017) Gutenberg-Richter law for deep earthquakes revisited: A dual-mechanism 798 hypothesis. Earth Plan Scie Lett 461:1-7. http://dx.doi.org/10.1016/j.eps1.2016.12.030

800 [2] Cornell CA (1968) Engineering seismic risk analysis. Bull Seism Soc Ame 58:1583-1606. 
802 [3] Faccioli E, Paolucci R (2005) Elementi di sismologia applicata all'ingeneria. Pitagora 803 Editrice, Bologna, Italy.

804

805 [4] IGME (2015) ZESIS: Base de Datos de Zonas Sismogénicas de la Península Ibérica y 806 territorios de influencia para el cálculo de la peligrosidad sísmica en España. 807 http://info.igme.es/zesis

808

809 [5] Carvalho, A., Modelação Estocástica da Acçao Sísmica em Portugal Continental, PhD 810 Thesis, University of Lisbon, Portugal, p. 392, 2007.

811

812 [6] Carvalho, A., Malfeito, N., Mapas de Perigosidade Sismica para Portugal Continental: Uma 813 Analise Critica, Parte I - Periodos de recorrencia de sismos, SPES, Lisbon, Portugal, 2018.

814

815 [7] Ministerio delle Infrastructure, NTC (Nuove Norme Tecniche per le Construzioni); 816 Ministerio delle Infrastructure, Rome, Italy, 2008.

817

818 [8] European Committee for Standardization (CEN), Design of structures for earthquake 819 resistance, Part 1: General rules, seismic actions and rules for buildings, BS EN 1998-1:2004, 820 Brussels, Belgium, 2004.

821

822 [9] Hariri-Ardebili, M.A.; Saouma, V.E. Seismic fragility analysis of concrete dams: A state823 of-the-art review. Eng. Struct. 2016, 128, 374-399.

824

825 [10] Zacchei, E., Molina, J.L., Reviewing arch-dams' building risk reduction through a 826 sustainability-safety management approach, Sustainability, 12, 1-24, 2020.

827

828 [11] Hutchings, L., Viegas, G., Application of empirical Green's functions in earthquake 829 source, wave propagation and strong ground motion studies, Earthquake Research and Analyses 830 - New Frontiers in Seismology, 2012, 88-140, 2012.

831

832 [12] Kramer, S. L., Geotechnical Earthquake Engineering, Prentice-Hall, Upper Saddle River, 833 New Jersey, 1 ed., 1996, p. 653. 
835 [13] Dicelis, G., Assumpção, M., Kellogg, J., Pedraza, P., Dias, F., estimating the 2008

836 Quetame (Colombia) earthquake source parameters from seismic data and InSAR measurements, Journal of South American Earth Sciences, 72, 250-265, 2016.

838

[14] Fergany E, Hutchings L (2017) Demonstration of pb-PSHA with Ras-Elhekma earthquake, 840 Egypt. NRIAG J Astr Geoph 6:41-51. http://dx.doi.org/10.1016/j.nrjag.2017.03.002

[15] Wolfram Mathematica 12, software version number 12.0, Wolfram Research, Inc., 2019.

843

844 [16] García, F., Aznárez, J.J., Padrón, L.A., Maeso, O., Relevance of the incidence angle of the 845 seismic waves on the dynamic response of ach dams, Soil Dynamics and Earthquake 846 Engineering, 90, 442-453, 2016.

848 [17] Aki, K., Richards, P.G., Quantitative Seismology, Ed. Jane Ellis, $2^{\circ}$ ed., p 743, 2002.

850 [18] Baker, M., Sutlief, S., Green's Functions in Physics, Version 1, p. 332, Seattle, 851 Washington, U.S., 2003.

852

853 [19] Portuguese Institute of Sea and Atmosphere (IPMA). Accessed on 17/05/2020. 854 http://www.ipma.pt/pt/geofisica/sismicidade/

856 [20] Bentz, S., Kwiatek, G., Martínez-Garzón, P., Bohnhoff, M., Dresen, G., Seismic moment 857 evolution during hydraulic stimulations, Geophysical Research Letters, 47, 1-9, 2020.

859 [21] Luzi, L., Puglia, R., Russo, E. and ORFEUS WG5, Engineering Strong Motion (ESM) 860 database, version 1.0. Istituto Nazionale di Geofisica e Vulcanologia, Observatories and 861 Research Facilities for European Seismology, 2016. Accessed May 2020. http://esm.mi.ingv.it. 862

863 [22] Sistema Nacional de Informação de Recursos Hidricos (SNIRH), database. Accessed May 864 2020, https://snirh.apambiente.pt/index.php?idMain=4\&idItem=2

866 [23] Barone, G., Lo Iacono, F., Navarra, G., Palmeri, A., A novel analytical model of power 867 spectral density function coherent with earthquake response spectra, ${ }^{\text {st }}$ ECCOMAS Thematic 
868 Conference on Uncertainty Quantification in Computational Sciences and Engineering, Crete 869 island, Greece, 25-27 May 2015.

870

[24] Seismosignal, Version 4.0.0, Seismosoft Ltd, Pavia, 2010.

872

873 [25] António, J., Tadeu, A., 3D seismic response of a limited valley via BEM using 2.5D 874 analytical Green's functions for an infinite free-rigid layer, Soil Dynamics and Earthquake 875 Engineering, 22, 659-673, 2002.

876

[26] Zacchei, E., Molina, J.L., Artificial accelerograms to estimate damage of dams by using 878 failure criteria, Scientia Iranica (in press), 2018. doi:

879 https://dx.doi.org/10.24200/sci.2018.50699.1824

880

881 [27] Wennerberg, L., Stochastic summation of empirical Green's functions, Bulletin of the 882 Seismological Society of America, 80, 1418-1432, 1990.

883

884 [28] Stein, S., Wysession, M., An Introduction to Seismology, Earthquakes, and Earth 885 Structure, Ed. Blackwell Publishing Ltd., p. 515, 2005.

886

[29] Ji, Y., Wu, W., Zhao, Z., Unloading-induced rock fracture activation and maximum 888 seismic moment, Engineering Geology, 262, 1-13, 2019.

889

890 [30] Zacchei, E., Molina, J.L., Brasil, R., Seismic hazard assessment of arch dams via dynamic 891 modelling: an application to the Rules Dam in Granada, SE Spain, International Journal of Civil 892 Engineering, 2017, 1-10, 2017.

893

894 [31] Scordilis, E.M., Empirical global relations converting $M_{s}$ and $m_{b}$ to moment magnitude, 895 Journal of Seismology, 10, 225-236, 2006.

896

897 [32] Baruah, S., Baruah, S., Bora, P.K., Duarah, R., Kalita, A., Biswas, R., Gogoi, N., Kayal, 898 J.R., Moment magnitude $\left(\mathrm{M}_{\mathrm{w}}\right)$ and local magnitude $\left(\mathrm{M}_{\mathrm{L}}\right)$ relationship for earthquakes in 899 Northeast India, Pure and Applied Geophysics, 169, 1977-1988, 2012. 
901 [33] Hanks, T.C., Kanamori, H., A moment magnitude scale, Journal of Geophysical Research, $90284,2348-2350,1979$.

903

904 [34] Ross S.M., Probability and statistics for engineers and scientists, Apogeo Editor, Italy, p $905614,2008$.

906

907 [35] Ministério da Habilitação, Obras Públicas e Transportes, Regulamento de Solicitações em 908 Edifícios e Pontes (RSA), Lisbon, Portugal p. 34, 1983

909

910 [36] Jayaram, N., Lin, T., Baker, J.W., A computationally efficient ground-motion selection 911 algorithm for matching a target response spectrum mean and variance, Earthquake Spectra, 912 27(3), pp. 797-815, 2011.

913

914 [37] Mert, A., Fahjan, Y.M., Hutchings, L.J., Pinar, A., Physically based probabilistic seismic 915 hazard analysis using broadband ground motion simulation: A case study for the Prince Islands 916 Fault, Marmara Sea, Earth, Planet and Space, 68, 1-26, 2016.

917

918 [38] Sabetta, F., Lucantoni, A., Bungum, H., Bommer, J.J., Sensitivity of PSHA results to 919 ground motion prediction relations and logic-tree weights, Soil Dynamics and Earthquake 920 Engineering, 25, 317-329, 2005.

921

922 [39] Mulargia, F., Stark, P.B., Geller, R.J., Why is probabilistic seismic hazard analysis (PSHA) 923 still used, Physics of the Earth and Planetary Interiors, 264, 63-75, 2017.

924

925 [40] Chan, C.H., Wu, Y.M., Cheng, C.T., Lin, P.S., Wu, Y.C., Scenario for a short-term 926 probabilistic seismic hazard assessment (PSHA) in Chiayi, Taiwan, Terr. Atmos. Ocean. Sci., $927 \quad 24,671-683,2013$.

929 [41] Kutanis, M., Ulutas, H., Isik, E., PSHA of Van province for performance assessment using 930 spectrally matched strong motion records, J. Earth Syst. Sci., 127, 1-14, 2018.

932 [42] Soysal, B.F., Ay, B.Ö., Arici, Y., Evaluation of the ground motion scaling procedures for 933 concrete gravity dams, Procedia Engineering, 199, pp. 844-849, 2017. 
935 [43] Ahulu, S.T., Danuor, S.K., Asiedu, D.K., Probabilistic seismic hazard assessment of 936 southern part of Ghana, J Seismol, 22, 539-557, 2018.

938 [44] Pailoplee, S., Sugiyama, Y., Charusiri, P., Deterministic and probabilistic seismic hazard 939 analyses in Thailand and adjacent areas using active fault data, Earth Planets Space, 61, 1313$9401325,2009$.

942 [45] Silacheva, N.V., Kulbayeva, U.K., Kravchenko, N.A., Probabilistic seismic hazard 943 assessment of Kazakhstan and Almaty city in peak ground accelerations, Geodesy and 944 Geodynamics, 9, 131-141, 2018.

946 [46] Jiménez, M.J., García-Fernández, M., \& GSHAP Ibero-Maghreb Working Group, Seismic 947 hazard assessment in the Ibero-Maghreb region, Annali di Geofisica, 42, 1057-1065, 1999.

949 [47] Le Goff, B., Borges, J. F., Bezzeghoud, M., Intensity-distance attenuation laws for the 950 Portugal mainland using intensity data points, geophysical Journal International, 199, 1278951 $1285,2014$.

952

[48] Douglas, J., Ground Motion Prediction Equations 1964-2019, Database, 2019. Link: http://www.gmpe.org.uk/gmpereport2014.html

[49] Ambraseys, N.N., Douglas, J., Sarma, S.K., Smit, P.M., Equations for the estimation of strong ground motions from shallow crustal earthquakes using data from Europe and the Middle East: Horizontal peak ground acceleration and spectral acceleration, Bulletin of Earthquake

[50] De Sousa, R.R., Costa, A.C., Costa, A., Metodologia para a Avaliação da Segurança

962 Sísmica de Edifícios Existentes baseada em Analises de Fiabilidade Estrutural, Relatório 963 81/2019 - DE/NESDE, LNEC, p. 148, 2019.

965 [51] Hutchings, L., Stavrakakis, G.N., Ioannidou, E., Wu, F.T., Jarpe, S., Kasameyer, P., Strong 966 ground motion synthesis for a M=7.2 earthquake in the Gulf of Corinth, Greece using empirical 967 Green's functions, $29^{\text {th }}$ IASPEI General Assembly, Thessaloniki, Greece, August 18-28, 1997. 
969 [52] Hutchings, L., Kinematic earthquake models and synthesized ground motion using 970 empirical Green's functions, Bulletin of the Seismological Society of America, 84, 1028-1050, 9711994.

972

973 [53] Hutchings, L., Modeling earthquake ground motion with an earthquake simulation 974 program (EMPSYN) that utilizes empirical Green's functions, Technical Report UCRL-ID975 105890, p. 119, 1992.

976

977 [54] Sorensen, M.B., Pulido, N., Atakan, K., Sensitivity of ground-motion simulations to 978 earthquake source parameters: A case study for Istanbul, Turkey, Bulleting of the Seimsologicla 979 Society of America, 97, 881-900, 2007.

980

981 [55] Clough, R. W., Penzien, J., Dynamics of Structures, McGraw-Hill, New York, USA, $3^{\text {a }}$ 982 Edition, p. 752, 2003.

983

984 [56] Luque, L., Lario, J., zazo, C., Goy, J.L., Dabrio, C.J., Silva, P.G., Tsunami deposits as 985 paleoseismic indicators: Example from the Spanish coast, Acta Geologicahispanica, 36, 197$986211,2001$.

987

988 [57] Gràcia, E., Dañobeita, J., Vergés, J., Mapping active faults offshore Portugal ( $\left.36^{\circ} \mathrm{N}-38^{\mathrm{a}} \mathrm{N}\right)$ :

989 Implications for seismic hazard assessment along the southwest Iberian margin, Geology, 31, $99083-86,2003$.

991

992 [58] Gutscher, M.A., Baptista, M.A., Miranda, J.M., The Gibraltar Arc seismogenic zone (part 993 2): Constraints on a shallow east dipping fault plane source for the 1755 Lisbon earthquake 994 provided by tsunami modelling and seismic intensity, Tectonophysics, 426, 153-166, 2006. 995

996 [59] Thiebot, E., Gutscher, M.A., The Gibraltar Arc seismogenic zone (part 1): Constraints on 997 a shallow east dipping fault plane source for the 1755 Lisbon earthquake provided by seismic 998 data, gravity and thermal modeling, Tectonophysics, 426, 135-152, 2006.

1000 [60] Cunha, T.A., Matias, L.M., Terrinha, P., Negredo, A.M., Rosas, F., Fernandes, R.M.S., 1001 Pinheiro, L.M., Neotectonics of the SW Iberia margin, Gulf of Cadiz and Alboran Sea: A 
1002 reassessment including recent structural, seismic and geodetic data, Geophysical Journal 1003 International, 188, 850-872, 2012.

1004

1005 [61] Matias, L.M., Cunha, T., Annunziato, A., Baptista, M.A., Carrilho, F., Tsunamigenic 1006 earthquakes in the Gulf of Cadiz: Fault model and recurrence, Nat. Hazards earth Syst. Sci., 13, $1007 \quad 1-13,2013$.

1008

1009 [62] Woessner, J. et al., The 2013 European seismic hazard model: Key components and results, 1010 Bull. Earthquake Eng., 13, 3553-3596, 2015.

1011

1012 [63] Carvalho, J., Dias, R., Ghose, R., Teves-Costa, P., Borges, J., Narciso, J., Pinto, C., Leote, 1013 J., Near-surface characterization of the Lisbon and Lower Tagus Valley area, Portugal, for 1014 seismic hazard assessment: VS30 and soil classification maps, Bulleting of the Seismological 1015 Society of America, 108, 2854-2876, 2018.

1016

1017 [64] Sousa, M.L., Costa, A.C., Ground motion scenarios consistent with probabilistic seismic 1018 hazard disaggregation analysis. Application to Mainland Portugal, Bull. Earthquake Eng., 7, 1019 127-147, 2009.

1020

1021 [65] Hutching, L., Mert, A., Fahjan, Y., Novikova, T., Golara, A., Miah, M., Fergany, E., 1022 Foxall, W., Physics-based hazard assessment for critical structures near large earthquake 1023 sources, Pure Appl. Geophys., 174, 3635-3662, 2017.

1024

1025

[66] Sousa, M.L., Oliveira, C.S., Hazard mapping based on macroseismic data considering the influence of geological conditions, Natural Hazards, 14, 207-225, 1997.

1027

1028

[67] Fonseca, J.F.B.D., Vilanova, S.P., Comment on Sousa, M. L. and Costa, A. C., "Ground 1029 motion scenarios consistent with probabilistic seismic hazard disaggregation analysis", Bull. Earthquake Eng., 9, 1289-1295, 2011. active intraplate region, Gujarat, India, J. Earth Syst. Sci., 129, 1-9, 2020. 
1035 [69] Vrettos, C., Dynamic response of soil deposits to vertical SH waves for different rigidity depth-gradients, Soil Dynamics and Earthquake Engineering, 47, 41-50, 2013.

1037

1038 [70] McGarr, A., On a possible connection between three major earthquakes in California and oil production, Bulletin of the Seismological Society of America, 81, 948-970, 1991.

[71] Kono, Y., Nakamoto, K., Hiramatsu, Y., Temporal variation in seismic moment release rate of slow slips inferred from deep low-frequency tremors in the Nankai subduction zone, earth, Planets and Space, 72, 1-9, 2020.

1044

[72] Ren, J., Zhang, S., estimation of recurrence interval of large earthquake on the central Longmen Shan fault zone based on seismic moment accumulation/release model, Hindawi Publishing Corporation, 2013, 1-8, 2013.

[73] Valentini, A., Pace, B., Boncio, P., Visini, F., Pagliaroli, A., Pergalani, F., Definition of seismic input from fault-based PSHA: Remarks after the 2016 central Italy earthquake sequence, Tectonics, 38, 595-620, 2019.

[74] Jeremias, F.T., Carvalho, A., Coelho, A.G., Costa, A.C., Seismological studies for definition of design earthquake for hydroelectric scheme of Foz Tua site, XIII National Congress of Geotechnical, Lisbon, Portugal, 17-20 Abril, 2012.

[75] Kodur, V.K.R., Naser, M.Z., Importance factor for design of bridges against fire hazard, Engineering Structures, 54, 207-220, 2013.

1060 [76] García-Pérez, J., Castellanos, F., Díaz, O., Occupancy importance factor in earthquake 1061 engineering, Engineering Structures, 27, 1625-1632, 2005.

1063 [77] Pozos-Estrada, A., Liu, T.J., Gomez, R., Hong, H.P., Seismic design and importance 1064 factor: Benefit/cost for overall service time versus per unit service time, Structural Safety, 58, 1065 40-51, 2016. 
1067 [78] Peláez, J.A., Delgado, J., Casado, C.L., A preliminary probabilistic seismic hazard 1068 assessment in terms of Arias intensity in southeastern Spain, Engineering Geology, 139-151, 10692005.

1070

1071 [79] Zacchei, E., Molina, J.L., Introducing importance factors (IFs) to estimate a dam's risk of 1072 collapse produced by seismic processes, International Journal of Disaster Risk Reduction, 60, $10731-13,2021$. 